\title{
A Critical Review of Water Uptake by Shales
}

\author{
Harpreet Singh \\ National Energy Technology Laboratory, Morgantown, West Virginia, USA
}

\begin{abstract}
The shale boom in North America started more than a decade ago, however, the issue of substantial fracturing fluid loss inside shale did not draw much attention for a decade. In the past few years, many researchers conducted laboratory experiments to 1) observe various processes by which water imbibes into shale rocks, and 2) understand the mechanisms behind each process that contributes to fluid uptake in shale. Although there is consistency in most of the observations that control the liquid filling in shales, some issues remain in regards to wettability. Many mechanisms seem to be contributing to liquid filling in the laboratory experiments, but there is no consensus on the dominant mechanisms. Even though some observations from field provide consistent signatures, we do not yet have a verified answer for the geo-mechanisms behind those observations.

This paper provides a critical review of the observations (laboratory and field), the mechanisms behind those observations, and the models to mimic the imbibition behavior of shales. In this regard, following contents are critically reviewed: 1) history of imbibition in shales, 2) laboratory observations, 3) field observations, 4) mechanisms of water imbibition in shales, and 5) simulation models. We also discuss evaporation of water in shale as an additional mechanism that has not been proposed before, but may be contributing to the loss of water in shale formations.
\end{abstract}

\section{INTRODUCTION}

Problem of water retention in oil and gas reservoirs was first described a century ago by Mills and Wells (1919) where they discussed water-related issues in the Appalachian oil and gas fields. However, more recently this problem has been revisited in the context of fracturing fluid loss in shale reservoirs. Economical production from shale formations requires creating hydraulic fractures by pumping large volume of water $(\sim 2-6$ million gallons) with proppants at high pressure to keep the fractures from closing. Once the fracturing job is completed, the injection pressure is reduced and the fracturing fluid is allowed to flow back from the well for a brief period ( $\sim 10$ days) before shutting-in the well for a longer period ( $\sim$ few weeks to months) to prepare for the hydrocarbon

production. Sometimes, after fracturing operation the well is shut-in without a brief flow back period. On average, only $6-10 \%$ of the injected water is recovered in the US across all shale plays (Vandecasteele et al. 2015; Mantell 2013), whereas the unrecovered part of the injected fluid is believed to be imbibed by surrounding shale matrix, microfractures and other fracture network through various mechanisms. The recovered amount of water tends to be two times more in the case of liquid shale plays (Bakken, Eagle Ford, Mississippi Lime) compared to the recovered amount in the case of dry gas shale plays 
(Barnett, Marcellus, Haynesville). The lowest reported amount for recovered water has been $5 \%$ for the Haynesville shale (primarily dry gas), while the highest reported amount has been $48 \%$ for the Mississippi Lime (primarily oil). One of the most prolific shale play in the US, Eagle Ford, has produced less than $20 \%$ of the injected fracturing fluid in its entire production history (Nicot and Scanlon 2012). This abundant retention of fracturing fluid inside the shale formations is a cause of major concern because it keeps the hydrocarbons from flowing out of the reservoir by reducing the relative permeability of the hydrocarbons inside the formation.

Low recovery of fracturing fluid could be due to a number of different mechanisms, such as i) retention within fractures due to fracture volume closure during early flowback depletion (Ezulike et al. 2015), and/or ii) imbibition into the shale matrix due to capillary forces (Settari et al. 2002; Cheng 2012) and electro-chemical forces (Xu and Dehghanpour 2014; Zolfaghari et al. 2016; Binazadeh et al. 2016; Roshan et al. 2016). The focus of this paper is to summarize and analyze the published laboratory and field observations. We also discuss various mechanisms that contribute to loss of fracturing fluid inside shale and a brief review of simulation models.

\section{BRIEF HISTORY OF IMBIBITION IN SHALES}

Bell and Cameron (1905), Lucas (1918) and Washburn (1921) investigated the fluid invasion in the capillaries of constant cross section with negligible gravity and inertia. They found that the fluid in the capillary rises as a square root of time $(l(t) \propto$ $\sqrt{t}$ ), and that result is popularly referred to as the Lucas-Washburn (LW) equation. Traditionally, imbibition in a homogeneous porous media has been described by the Handy (1960) model, who developed a famous gas-water imbibition expression by equating the velocity from Darcy's law with the velocity of a piston like displacement obtained from mass-balance of two immiscible fluids. Handy (1960), obtained an

equation for the volume of the mass imbibed as a function of time that scaled as $\sqrt{t}$, which incidentally, is similar to the scaling of imbibition length $(\propto \sqrt{t})$ given by LW equation. Spontaneous imbibition in conventional reservoir rocks is primarily driven by capillary force, and it is known to be mainly influenced by tortuosity and reservoir heterogeneity (Cai and Yu 2011). Satisfactory advancements have been made to account for these properties on imbibition dynamics in conventional reservoir rocks using fractal theory (Cai et al. 2012; Cai et al. 2010).

Compared to our mature knowledge of imbibition in conventional reservoir rocks, research on imbibition in shales is still developing. Research on imbibition in shales gained some attention with the study of Roychaudhuri et al. (2011) who investigated the impact of spontaneous imbibition on gas production through experiments performed on shale samples. Prior to that, two modeling studies (Settari et al. 2002; Cheng 2012) had hypothesized that the poor recovery efficiency of fracturing fluid is due to capillary imbibition in shale matrix. Based on laboratory observations from past few years, it is known that the imbibition length in shales deviates significantly from the Handy model, 
or in other words the time exponent deviates from 0.5 by a significant margin $(\mathrm{Hu}$ et al. 2012; Roychaudhuri et al. 2013; Hu and Ewing 2014; Liu et al. 2015; Hu et al. 2015; Yang et al. 2016). Currently, there is no unique theory to explain this deviation, but different studies attribute this deviation to different reasons, for example low pore connectivity in shales (Hu et al. 2012; Hu et al. 2015), complex microstructure consisting of natural/micro-fractures and tight matrix (Yang et al. 2016; Sun et al. 2015), clays and different rock mineralogy (Ge et al. 2015; Roshan et al. 2016; Makhanov et al. 2014), and osmotic effects (Xu and Dehghanpour 2014; Zolfaghari et al. 2016; Binazadeh et al. 2016; Roshan et al. 2016). Even though the research on imbibition in shale is only a few years old, previous knowledge from the field of micro- and nanofluidics (Huber 2015; Li 2008) suggest that the geometry of the medium, the fluid-wall interaction, the fluidity and capillarity of the liquid imbibed, all play an important role in determining the volume of imbibition. However, the imbibition dynamics in shale is more complex than in nanofluidic devices because of the i) heterogeneity in pores types and its geometries, and ii) electro-chemical forces due to clay hydration and osmosis.

\section{LABORATORY OBSERVATIONS}

Since Roychaudhuri et al. (2011) reported that significant fractions of the injected fracturing fluid can be absorbed by the shale, many experimental studies have been conducted to study the imbibition of fluids in shale. Evidently, most of the experiments report consistent results, while some studies have reported contradictory observations. Here, we only present typical observations that have been reported in the literature. Observations from laboratory experiments are reported in two different sections in order to separate two different mechanisms of imbibition - i) imbibition due to capillary forces, and ii) imbibition due to electro-chemical forces.

\subsection{Typical Imbibition Behavior in Shales}

Imbibition of a liquid in a medium is generally characterized by a curve between the length of liquid intake versus square root of time. The slope of that curve represents the rate of imbibition, and the maximum imbibition length is given by the peak value of the curve. Typical behavior of liquid imbibition in a Berea sandstone consistently shows 0.5 slope on a log-log plot between liquid intake and time for various samples (Hu et al. 2012). However, imbibition experiments performed on various shale rocks from China produce a curve that depict multiple regions with slope values that can vary from 0.1 to greater than 0.5 on a log-log scale (Yang et al. 2016), whereas the slopes of the curves obtained from shale formations in the US depict a consistent value of 0.25 (Hu et al. 2012; $\mathrm{Hu}$ et al. 2015). This anomalous behavior in shales has been attributed to two reasons, which are coupled together: i) poor pore connectivity and highly heterogeneous pore network, and ii) presence of clays. 


\subsection{Imbibition Due to Capillary Forces}

\subsubsection{Wettability and Fluid Properties}

\subsubsection{Wettability}

The wettability of a rock is one of the key factors that control the imbibition dynamics through capillary pressure. The wettability of shale reservoir rocks has been experimentally investigated by a number of researchers for shale rocks across the US (Odusina et al. 2011; Wang et al. 2012), Canada (Borysenko et al. 2009; Makhanov 2013; $\mathrm{Xu}$ and Dehghanpour 2014; Lan et al. 2014; Lan et al. 2015), Australia (Roshan et al. 2016), China (Liang et al. 2016) and Poland (Ksiezniak et al. 2015). Lan et al. (2014; 2015) studied the effect of wettability on the imbibition dynamics by comparing the behaviors of water and oil phases on rock samples from two shale plays in Western Canada, the Montney and Horn River. They observed that the oil completely spreads on the shale sample, while water droplets show a measurable contact angle that is greater than $37^{\circ}$, therefore, they concluded that the observed wettability cannot be fully explained by the contact angle results. They suggested that the wettability of shale rocks i) is affected by the connectivity of hydrophobic and hydrophilic pores, and ii) has strong affinity for oil in presence of degraded bitumen. Similar behavior was observed by Liang et al. (2016) for shale samples from Lower Longmaxi formation in China, although the contact angle for water varied between $12^{\circ}$ to $37^{\circ}$ at elevated and normal temperature, respectively. Wang et al. (2012) tested core samples from three wells in Bakken formation, and majority of the results showed that the samples were generally oil-wet or intermediate-wet. Odusina et al. (2011) studied samples from three shale plays (Eagle Ford, Barnett, and Floyd strata) that showed oil-wet or mixed-wet nature. Ksiezniak et al. (2015) studied the wettability of shale rock samples from Baltic Basin, Poland, and found the contact angle of oil to be almost two-times smaller $\left(44^{\circ}\right)$ than the contact angle for water $\left(85^{\circ}\right)$. Roshan et al. (2016) studied the wettability of a shale sample from a nominated $\mathrm{CO}_{2}$ storage site in New South Wales, Australia, for various pressures and temperatures. They observed that the contact angle for oil varied between $6^{\circ}$ to $18^{\circ}$, whereas the contact angle for water with salt varied between $17^{\circ}$ to $62^{\circ}$ at various pressure and temperature conditions. Josh et al. (2012) studied different shale samples using NMR techniques and observed that illitic shales tend to be strongly water-wet while the shale with kaolinitic clays tend to be oil-wet. Xu and Dehghanpour (2014) tested the shale samples from Horn River Basin, Canada, for wettability by isolating the factors that are responsible for the excess water imbibition and observed that the connected pore network of the intact samples is water-wet while the majority of the rock, including poorly connected pores, is oil-wet. They support their finding by suggesting that the oil spreads completely on fresh surfaces of the rock, while the pores of intact rock are wetted by a film of water and/or covered by precipitated salt that gives the pores a preference of water over oil. Ghanbari and Dehghanpour (2015) and Xu and Dehghanpour (2014) reported that wettability cannot be fully explained by the traditional 
definition of contact angle test, because they observed different wettability results for Horn River Basin sample by contact angle measurement and by imbibition experiments.

To summarize, observations from most of the experiments on shale rocks from various formations around the world suggest that kerogen-rich shales tend to have a higher affinity for oil than for water. However, some authors (Ghanbari and Dehghanpour 2015; $\mathrm{Xu}$ and Dehghanpour 2014) reported obtaining conflicting results for wettability when they used different method of measurement, and suggested that contact angle measurement is not an efficient method for estimating shale wettability. Later in section 5.1.1., we provide a physical explanation for this contradiction in wettability from two different methods and suggest a modified method for contact angle measurements that can rectify this discrepancy.

\subsubsection{Fluid Properties}

Several authors (Dehghanpour et al. 2013; Makhanov 2013; Makhanov et al. 2014; Odusina et al. 2011) have observed that shales imbibe more water than oil. They ascribe this phenomenon to absorption of water molecules by clays, which could also generate micro-fractures and, as a result, increase sample permeability. Most of these authors also observed that the normalized imbibed mass of oil phase is higher than that of water phase at initial times, which they ascribe to general affinity for oil (oil-wet) by the shales. However, oil imbibition rate gradually decreases and reaches a plateau sooner than water phase because, unlike water, oil phase does not have affinity to absorb on clay. Figure 1 shows a schematic that summarizes the general imbibition behavior of oil and water within the same sample of rock.

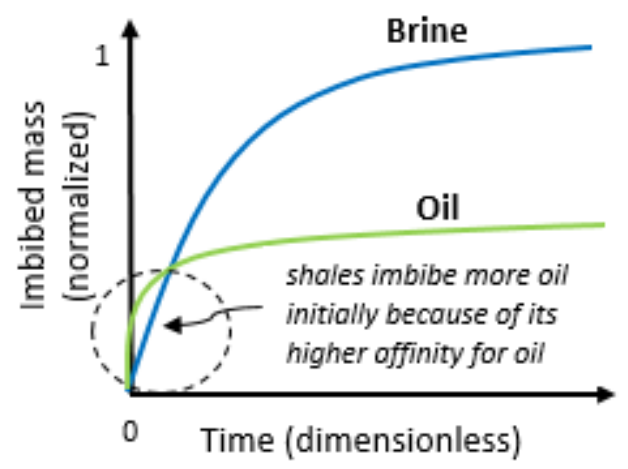

Figure 1: Schematic to summarize the general imbibition behavior of oil and water within the same sample of rock

Wang et al. (2015) investigated the effect of interfacial tension and viscosity of fracturing fluid on imbibition dynamics using artificial and natural cores from Ordos Basin in China. They observed that interfacial tension has a non-monotonic effect on the imbibition, such that imbibition is maximum for an optimum value of interfacial tension. They suggested that theoretically capillary force increases with the increase in interfacial tension, but beyond a certain critical limit any increase in interfacial tension would 
enlarge the emulsified oil droplets, which can increase resistance to the imbibing fracturing water. They also reported that amount of imbibition decreases with the increase in viscosity of the fracturing fluid, though the effect levels off beyond a certain limit of viscosity.

Several authors (Zhou et al. 2014; Morsy and Sheng 2014; Makhanov et al. 2014) have investigated the effect of fracturing fluid compositions on imbibition dynamics in shale. Zhou et al. (2014) used shale samples from four different formations in the Horn River Basin in Canada and observed that the effect of fracturing fluid composition strongly depends on the clay content of shale rocks. They found that for shale with higher clay content, $2 \% \mathrm{KCl}$ and $2 \% \mathrm{KCl}$ substitute (two different fracturing fluids) imbibed $10 \%$ to $40 \%$ less than $0.07 \%$ friction reducer (as fracturing fluid); whereas, for shale with low clay content, $0.07 \%$ friction reducer is imbibed $10 \%$ to $30 \%$ less than $2 \% \mathrm{KCl}$, but no noticeable difference was found between $0.07 \%$ friction and $2 \% \mathrm{KCl}$ substitute. Morsy and Sheng (2014) used shale samples from Barnett formation and reported two important observations: i) high $\mathrm{pH}$ solutions mixed with distilled water resulted in pore plugging due to combination of clay swelling and mineral dissolution, whereas high $\mathrm{pH}$ solutions mixed with higher alkaline concentrations $(2 \mathrm{wt} \% \mathrm{NaOH})$ resulted in severely damaging the samples, ii) low $\mathrm{pH}$ solutions induced bedding cracks resulting in accelerating the imbibition. Makhanov et al. (2014) used several shale samples from Horn River Basin in Canada and reported two main observations: i) use of xanthan gum results in significant imbibition despite its high viscosity, ii) anionic surfactants can reduce imbibition rates by reducing the surface tension, which is reduced further if the surfactant is mixed with $\mathrm{KCl}$ salt.

\subsubsection{Fractures, Micro-fractures and Matrix}

Pore structure of shale rocks is a complex system of matrix with organic and inorganic pores, micro-fractures, natural fractures and hydraulic fractures (Gale et al. 2014; Loucks et al. 2012). There is a raging debate in the literature about which of those pores contribute to the fluid flow most and at what time during the life of the reservoir. In the similar context, some authors believe that the loss of fracturing fluid in the shale is primarily because of imbibition into the fractures, where the liquid stays as an immobile phase due to capillarity, fracture closure and gravity segregation (Fan et al. 2010; Gdanski et al. 2009; Ehlig-Economides and Economides 2011; Parmar et al. 2014). These authors argue that the contribution of matrix to the liquid imbibition is negligible because of its ultra-low permeability that restricts the mobility of water into the matrix. However, a recent study by O'Malley et al. (2015) observed that most of the imbibed water resides in the matrix with a lesser amount in the fractures. They demonstrate this by calculating the volume of all the fractures and the matrix associated with a core data obtained from a representative site. They calculate the volume of fractures by characterizing the core data with a discrete fracture network, while the volume of matrix was calculated by using pore-scale and continuum scale models. 
Recently, many publications have reported that micro-fractures, which can take up a significant amount of water, are created due to swelling of clays by absorbing water molecules (Makhanov et al. 2014; Roshan et al. 2015; Sun et al. 2015; Zhou et al. 2016; Meng et al. 2015). As expected, imbibition of oil should create fewer micro-fractures compared to imbibition of water, and this was demonstrated by Makhanov (2013) as shown in Figure 2. Roshan et al. (2015) found that the formation of micro-fractures by crystalline swelling is much slower under confining pressure compared to when the shale sample is unconfined and allowed to swell freely. Yang et al. (2015) studied the creation of micro-fractures induced by water imbibition in the laboratory using the shale samples from Longmaxi formation in China. They found that micro-fractures are concentrated in the organic-rich intervals that have lower grain density and high porosity. Yang et al. (2015) suggested that large volume \% of total organic content facilitates the propagation of micro-fractures in organic-rich intervals.

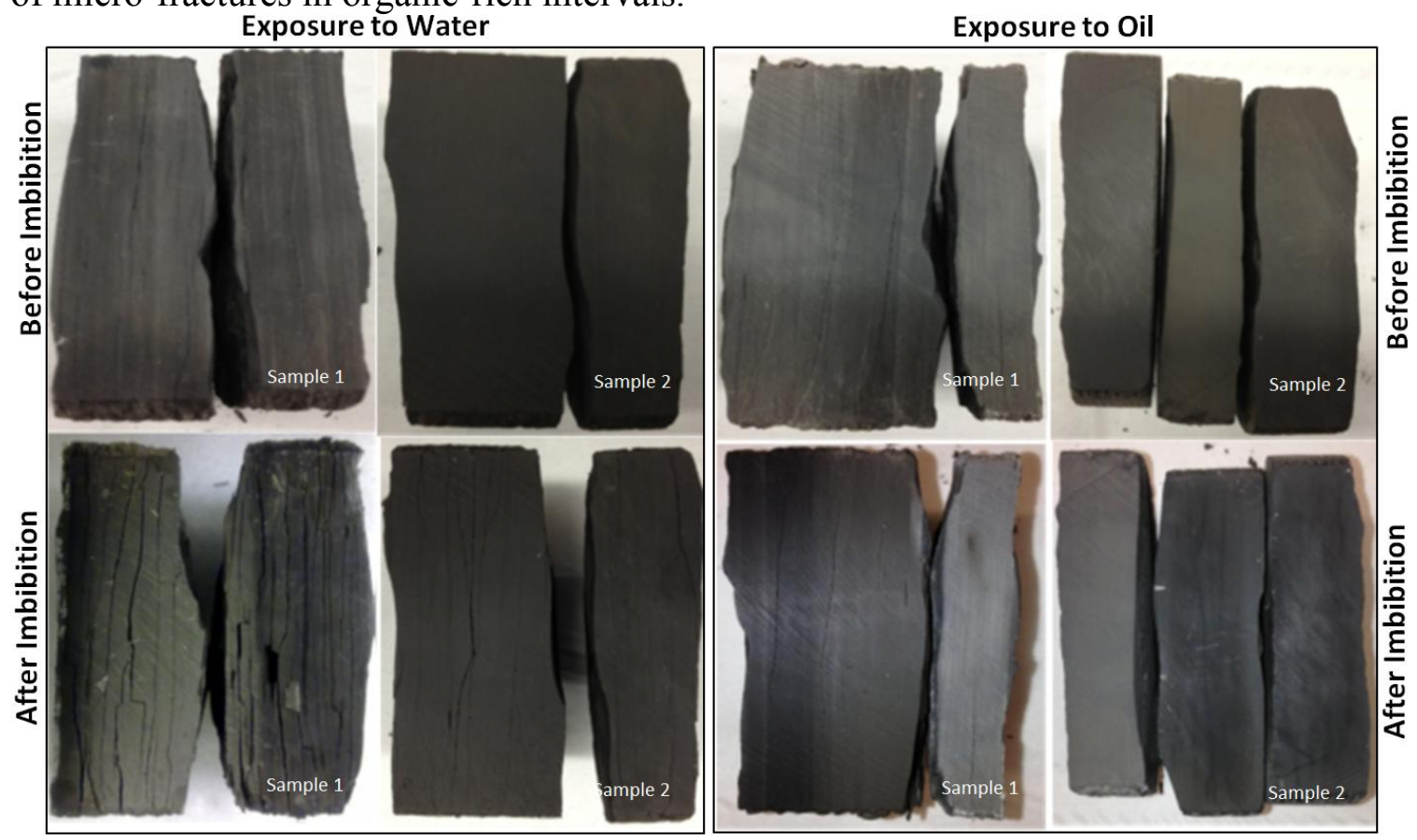

Figure 2: Shale samples (from Makhanov 2013) before and after exposure to water (left) and oil (right)

Even though there is no verified explanation yet about what physical processes create micro-fractures during imbibition, three hypothesis have been given in the literature, which are: i) micro-fractures may be induced due to high internal pore pressure generated by the capillary pressure (Yang et al. 2015) ii) micro-fractures are created by crystalline swelling that also eventually lead to the collapse of the sample due to extension of repelling forces between clay minerals at both interlayers and outer-layers (Roshan et al. 2015), iii) micro-fractures are created due to lubrication effect of the imbibing fluid, which is caused by one of the three processes (Zhou et al. 2016) -a) shear 
and tensile failure, b) some physical or chemical reactions between imbibed fluid with micro-fracture surfaces, c) clay swelling by water absorption can crack and reopen microfractures. Based on the results of Makhanov (2013) in Figure 2, it seems that swelling of clay is not the only mechanism that creates micro-fractures, because some microfractures are also created with the imbibition of oil despite having no affinity for absorption in clays.

Meng et al. (2015) and Zhou et al. (2016) investigated the effect of imbibition on permeability of matrix, natural fractures, and micro-fractures. Meng et al. (2015) used the pulse-decay technique to measure the permeability of four shale samples from Long-maxi Formation in China with imbibition over a period of about 1.7 days. They observed the appearance of micro-fractures on the surface of the shale samples as the sample soaked more water, while the overall permeability of the rock fluctuates greatly with time. Zhou et al. (2016) conducted a more extensive investigation with 5 samples from Niobrara, 5 samples from Horn River, and 3 samples from Woodford shale over a period of about 40 days. They used the pressure build-up method to measure the permeability of shale samples with time over a period of about 40 days. In summary, they observed a reduction in matrix permeability and natural fractures due to clay swelling, where the reduction gets worse with increase in imbibed volume. They observed that this permeability damage in matrix and fractures was permanent, because the damage was caused by clay swelling, which is irreversible. Zhou et al. (2016) found that the permeability of micro-fractures increases during the imbibition process due to re-opening of micro-fractures. Even though there are some hypotheses proposed by Zhou et al. (2016) and Roshan et al. (2015) to explain the mechanism that causes the re-opening of micro-fractures as discussed above, they are only speculative in nature as they have not been tested. Figure 3 shows a schematic that summarizes the general effect of water imbibition on change in permeability for matrix, natural fractures, and micro-fractures, based on the short-term and long-term imbibition tests by Meng et al. (2015) and Zhou et al. (2016), respectively.

(a) Matrix and Natural Fractures:

decrease in permeability due to clay swelling

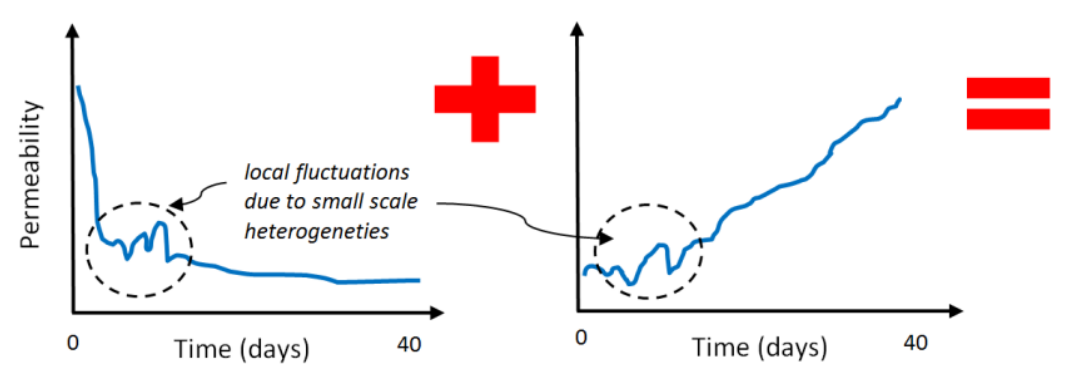

(b) Micro-fractures: increase in permeability due to their reopening
Figure 3: Schematic to summarize the general effect of water imbibition on change in permeability for a) matrix and natural fractures, b) micro-fractures, c) sample 


\subsubsection{Pore Size and Connectivity}

According to Young-Laplace equation $\left(P_{c}=2 \sigma \cos \theta / r\right)$, capillary force which drives the fluid inside spontaneously inside the pore against the viscous and resistive forces is higher for smaller size pores. Hence, for similar fluid properties the liquid will first fill inside the smaller pores with higher imbibition rate compared to larger pores. However, shale is a system of complex pores with varying heterogeneity not just in pore types and sizes, but also in mineralogy. It is believed that the smaller pores in shale have higher friction force that significantly resists the capillary imbibition of liquid inside them. On the contrary, larger pores in the shale provide less friction to the capillary flow such that the effective driving force due to capillary is positive. Therefore, as a result the liquid tends to enter the larger pores first in tight rocks compared to smaller pores. This hypothesis was tested by Meng et al. (2015) who by using low-field nuclear magnetic resonance (NMR) show that the water in bigger pores have a longer transversal relaxation time (T2), while the water in smaller pores have a short T2 signature. They showed that the peak area of the longer T2 signature that depicts the larger pores fills first and it does not change in time.

The amount of imbibition versus time for different types of tight rocks shows significant variation from one sample to another. This variation in imbibition curves among different shales is usually characterized by time exponent $n\left(V_{i m b} \propto t^{n}\right)$, which can vary from 0.1 to greater than 0.5 on a log-log scale (Yang et al. 2016), and in many cases it is estimated to be around 0.25 (Hu et al. 2012; Hu et al. 2015). Because of a lack of a constitutive relationship to explain the deviation in $n$ between different shales, some authors (Hu et al. 2015; Hu et al. 2015; Hu et al. 2012) attribute this to variation in pore size distribution and pore connectivity. They suggest that the rate of imbibition and the amount of liquid imbibed tend to decrease with decreasing pore connectivity, as summarized schematically in Figure 4.

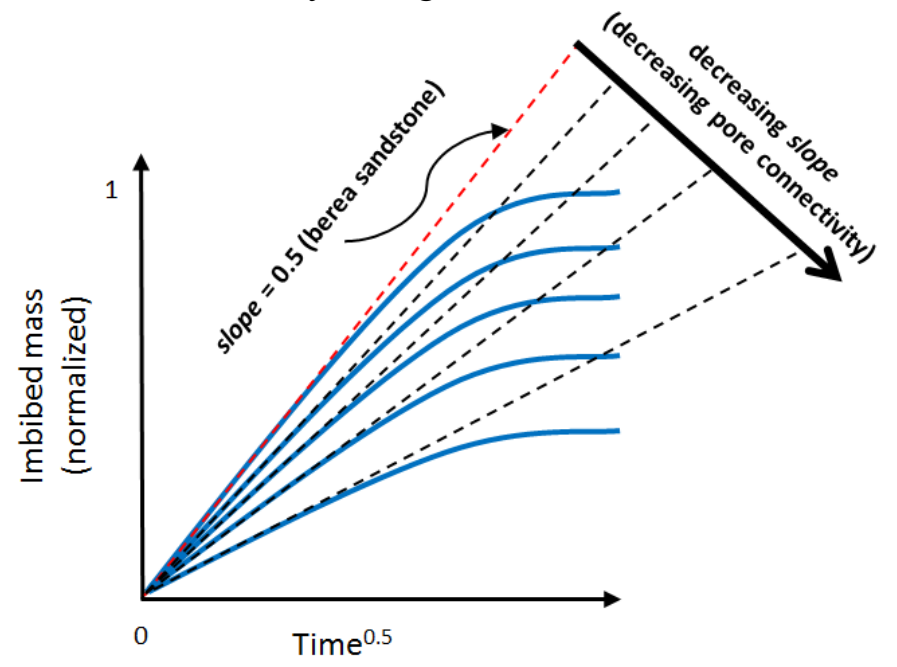

Figure 4: Schematic to summarize the general effect of pore connectivity on imbibition 
Yang et al. (2016) fitted the time exponent on several experimental imbibition data from different types of shale rocks and developed a criteria that can provide the value of time exponent $(n)$ based on the pore size distribution of a shale rock, as shown in Table 1.

Table 1: Imbibition characteristics for tight rocks (adapted from Yang et al. 2016). Parameters $n_{i}$ and $n_{L}$ represent the initial and late time exponents, respectively.

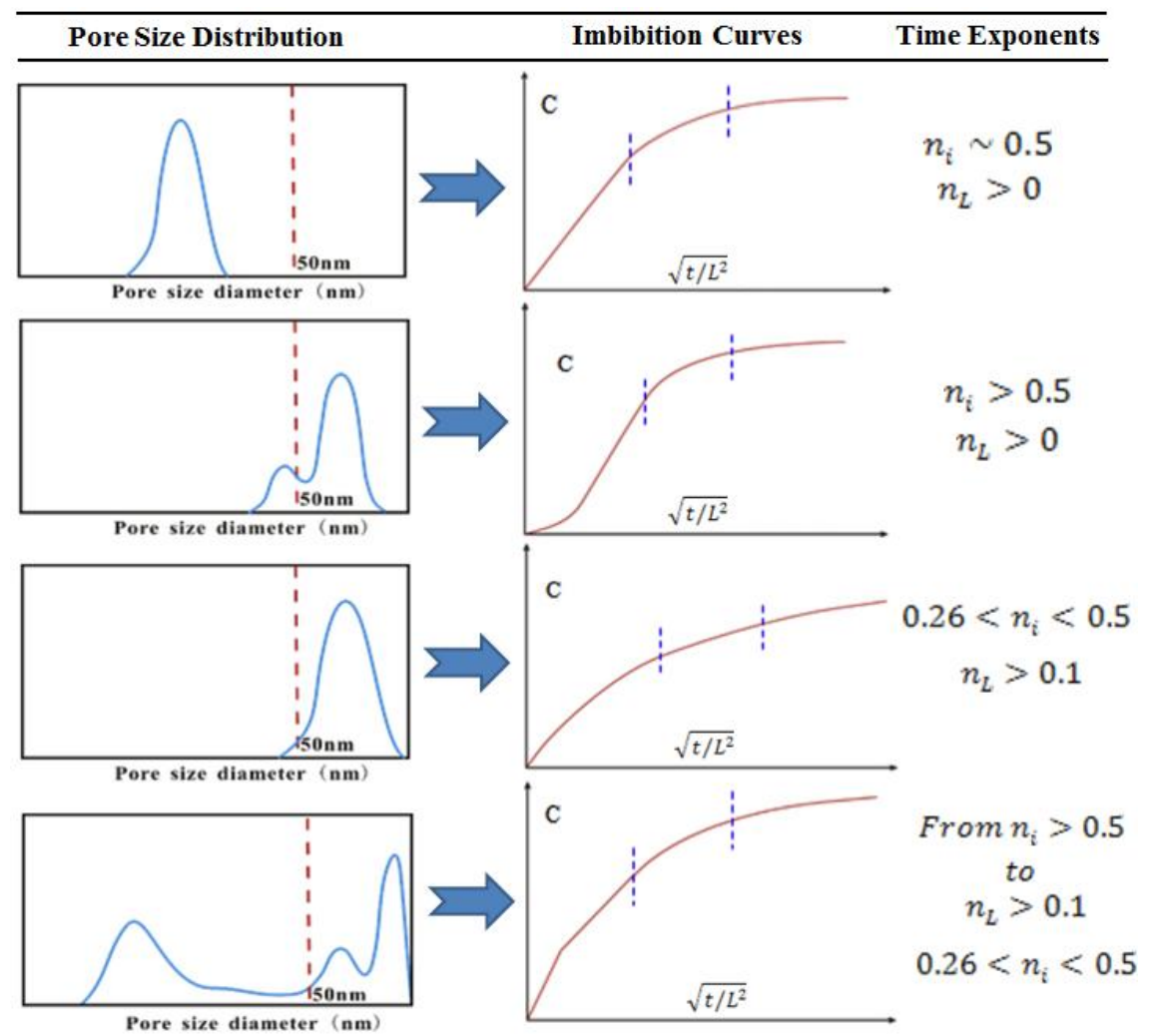

\subsection{Imbibition Due to Electro-Chemical Forces}

\subsubsection{Clay Hydration}

Clays play an important role in the amount of water imbibed in shales. When an aqueous solution is injected in organic rich shale, the charged regions of clay minerals absorb the water molecules through interlayer spaces in the clay mineral that initiate the osmotic forces. The process of water absorption by the clay minerals in the shale is referred in short as clay hydration. Several authors (Makhanov et al. 2014; Ge et al. 2015; Yang et al. 2016) have reported that imbibed volume in some samples can be greater than the initially measured pore volume, which they suggested was due to absorption of water molecules by the semi-permeable clay membranes. Yang et al. (2016) reported that this imbibed volume can be up to $400 \%$ of the pore volume measured before imbibition. Even though most types of clay minerals swell by absorbing water through inter- and outer- 
layers, some specific clays like smectite (particularly monmorillonite) and illite/smectite mixed-layer clay show significant swelling with water absorption (Gray et al. 1980; Roshan et al. 2016; Yang et al. 2016). Yang et al. (2016) suggest that the clay with high specific surface area has strong affinity for water absorption. Figure 5 shows a schematic that summarizes the general imbibition behavior as a function of clay content.

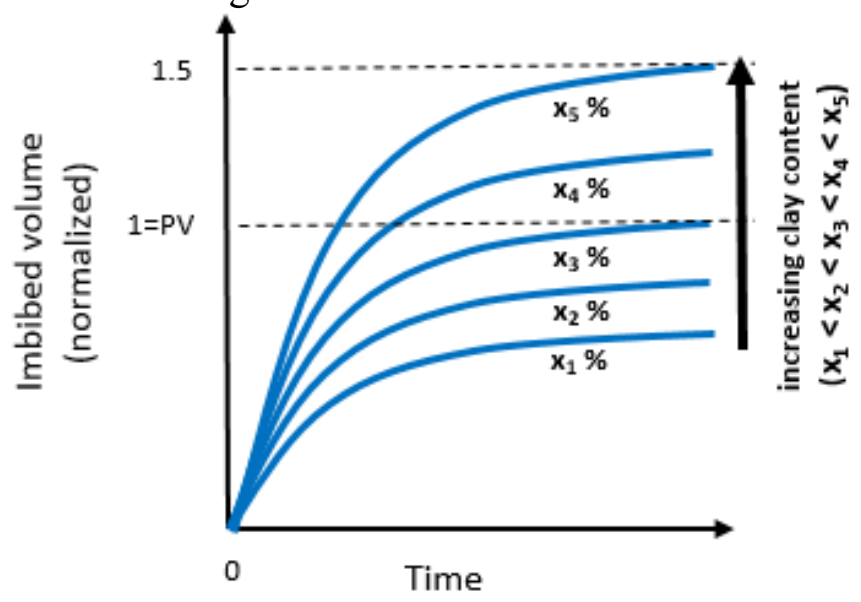

Figure 5: Schematic to summarize the general imbibition behavior as a function of clay content

\subsubsection{Osmosis}

Osmosis is a process by which a solvent (such as water) passes through a semipermeable membrane (e.g. clay minerals in shale) from a region of low solute concentration (low salinity) to a region of high solute concentration (high salinity), such that it tends to equilibrate the solute concentration on two sides of the semi-permeable membrane. At the equilibrium condition, osmotic pressure becomes equal to hydrostatic pressure. There are very few publications that investigate the role of osmosis as the imbibition mechanism in shale. Takeda et al. (2012) used siliceous shale core sample to investigate if osmosis can spontaneously imbibe the fluid inside the rock. They observed the pressure difference across the core started increasing sharply in less than a day due to flow from low-salt concentration to high-salt concentration induced by osmosis. Fakcharoenphol et al. (2014) performed low and high-salinity imbibition experiments using a laminated core from Bakken Formation. They observed that when clay particles are exposed to low-salinity water (injected fluid), the water molecules pass through the clay pore space and expel oil from the clay-rich laminations. They attribute this countercurrent imbibition due to an overlapping electric double layer (EDL) created by osmotic pressure, which is developed due to salinity contrast between the low-salinity injected water and high-salinity formation brine. Xu and Dehghanpour (2014) used samples from two wells in the Horn River Basin shale to investigate the effect of osmotic potential on the imbibition behavior. They observed that increasing the salt concentration of the imbibing water decreases the volume of the imbibed water. They attribute the decrease of 
imbibed volume to decrease in osmotic potential, which is created due to the difference between salt concentration in the pore water and the salinity of the injected water. The osmotic potential (also called chemical/osmotic potential or chemical/osmotic pressure) drives the water molecules from low-salinity water towards the high-salinity water until equilibrium is achieved, and increasing the salinity of the injected water decreases the osmotic pressure. Ghanbari and Dehghanpour (2015) used 22 samples from wells in the Horn River Basin shale to investigate the effect of rock fabric, and they observed that significant permeability parallel to the laminations act as a preferential pathway for the imbibing water than the semi-permeable clay layers, therefore, reducing the favorable conditions for the development of osmotic pressure. Roshan et al. (2016) used shale core sample from Evergreen Formation in Australia to investigate the mechanics of osmosis in the context of water imbibition in shale. They observed that the total imbibed water capacity decreases in the presence of higher ionic strength i.e. with the addition of $\mathrm{CaCl}_{2}$ and $\mathrm{MgCl}_{2}$ than with the addition of $\mathrm{NaCl}$ and $\mathrm{KCl}$. They suggest that water imbibition by osmosis is a function of the type and concentration of ions in the vicinity of clay minerals and in the bulk solution, because it affect the thickness of the diffusive double layer.

\section{Field ObSERVATIONS}

\subsection{Flow Rates Before and After Shut-in}

After a well is hydraulically fractured, a short period of time is allowed for the fracturing water to flow back from the reservoir. This flowback period is followed by a shut-in period that could vary from few weeks to few months, and after that the well is opened for production. Well production data available from four different shale plays the Bossier play in Texas (Settari et al. 2002), the Marcellus in Pennsylvania (Cheng 2012), the Montney Formation in British Columbia, Canada (Kanfar and Clarkson 2016), and the Monteith Formation in the Alberta, Canada (Zambrano et al. 2016) - show that the flow rates of water and oil/gas become much lower and higher, respectively, compared to their rates during flowback period (before shut-in). Ghanbari et al. (2013) analyzed the gas production data of 18 hydraulically-fractured horizontal wells from Horn River Basin and reported that the wells with low efficiency of flowback water have higher early-time gas production, whereas wells with high efficiency of flowback water have low early-time gas production.

As a mechanism for this observation, it is hypothesized that the fall in water rates after shut-in period (in some cases almost no water is produced after shut-in) could be the result of substantial amount of water being sucked into the matrix due to capillary imbibition and osmotic pressure. This hypothesis is supported by an increased oil/gas production rate after the shut-in period, which could have been pushed out by the imbibition of water into the matrix. However, it should be noted that this mechanism would be possible only if the shale matrix has higher affinity for aqueous fluid over 
hydrocarbon, or in other words the shale matrix is water-wet or mixed-wet rock (Fakcharoenphol et al. 2016).

\subsection{Salinity of Produced Water vs. Time}

Haluszczak et al. (2013) analyzed the salinity of the produced water from gas wells in the Marcellus formation and observed that the salinity (concentration of sodium, calcium, and chloride dissolved in water) of produced water increases significantly with time. Typical salinity of the fracturing fluid is in the range of $1000 \mathrm{ppm}$, whereas the salinity of the produced water analyzed by Haluszczak et al. (2013) increased up to 170,000 after about 3 months of fracking the well. This magnitude of salinity is about ten times greater than the salinity of the seawater. Similar trend of increase in flowback water salinity has been observed across Horn River Basin in Canada, Wattenberg Formation in Colorado and other shale plays (Blauch et al. 2009; Jiang 2013; Zolfaghari et al. 2016).

As a mechanism for this observation, Haluszczak et al. (2013) suggested that the high salinity of the flowback water could not be due to mineral dissolution because the $\mathrm{pH}$ of the flowback water was near neutral. Other authors (Jiang 2013; Chermak and Schreiber 2014; Zolfaghari et al. 2016) suggest that the near neutral pH of the flowback water is possible through dissolution reaction with the formation minerals. It is also widely assumed that the generation of highly saline produced water is through the mixing of injected fluid with the formation brine, based on binary mixing models of injected fluid with the homogeneous formation brine (Capo et al. 2014; Rowan et al. 2015; Renock et al. 2016). However, there are examples of heterogeneities in brine geochemistry, such as in Appalachian Basin, which suggest various stages of water-rock interactions (Warner et al. 2012). Ghanbari et al. (2013) suggested the increasing salinity of flowback water is the result of diffusion of ions from rock into the water with the salt precipitated from the pore water acting as the main source.

It should be noted that Mills and Wells (1919) who discussed water-related issues in the Appalachian oil and gas fields about a century ago reported this same observation on page 51. They mention that the proportion of salt in the waters collected from the same well increased as production continued. They also observed that during the time the well was not used (shut-in) large masses of salt were deposited in the rocks at the bottom of the wells or between the tubing and casing (page 44-47). Thus, their primary hypothesis for observing increased salinity in produced water was based on evaporative effects of expanding gas and salt deposition in gas wells and in the interstices of the productive rocks. The author's personal opinion aligns with the hypothesis of Mills and Wells (1919).

\section{3. pH of Produced Water vs. Time}

Haluszczak et al. (2013) analyzed the $\mathrm{pH}$ of the produced water with time from gas wells in the Marcellus formation and observed that the $\mathrm{pH}$ of the flowback water remains near neutral. Jiang (2013) found that that $\mathrm{pH}$ of the flowback water from two wells located in the Wattenberg Formation in Colorado remains near neutral with time. 
Interestingly, Jiang (2013) reported that even though the $\mathrm{pH}$ of the fracturing fluids used in these two wells were 5.0 and 10.2, respectively, flowback water from these two wells that were located close to each other and drilled to same depth, reported a near neutral $\mathrm{pH}$ with time. Zolfaghari et al. (2016) analyzed the pH from wells across Horn River Basin in Canada and observed that the $\mathrm{pH}$ values were slightly above 8 , though they noted that the $\mathrm{pH}$ measurements were done in the laboratory.

As a mechanism for this observation, Jiang (2013) hypothesized the dissolution of $\mathrm{CaCO}_{3}$ and $\mathrm{Al}_{2} \mathrm{O}_{3}$ (present in formation rocks) with fracturing fluid having acidic $\mathrm{pH}$, and the dissolution of $\mathrm{SiO}_{2}$ (present in formation rocks) with fracturing fluid having basic $\mathrm{pH}$.

\subsection{Barium in Produced Water vs. Time}

Renock et al. (2016) reported a general increase in Barium (Ba) concentration from wells in Marcellus shale across New York and Pennsylvania. Zolfaghari et al. (2016) analyzed the barium concentration in the flowback water from three wells across Horn River Basin in Canada and observed that the Ba concentration generally increased across all the wells with time. Jiang (2013) analyzed Ba concentration in the flowback water from two wells located in the Wattenberg Formation in Colorado and observed that its concentration rose with time, whether as dissolved or as suspended solids.

In order to understand the mechanism behind this observation, Zolfaghari et al. (2016) analyzed the rock samples to detect any barium in its mineralogy, but they observed no barium-bearing component in the bulk rock. Though, they observed veins of $\mathrm{Ba}$ on the surface of fracture as precipitated salt crystals from a sample they analyzed in the laboratory. They suggested that the concentration of Ba profile in the flowback could provide a signature of connectivity between natural and induced fractures, with steep slope concentration profile indicating a complex fracture network, while a small slope profile indicating a simpler and less dendritic fracture network. Unlike the samples of Zolfaghari et al. (2016), Renock et al. (2016) reported high Ba concentrations in the bulk samples from Marcellus shale in New York and Pennsylvania and they suggested that the Ba concentration in flowback water is released from mineral phases within the rock in addition to possible dilution of formation brines by injected fracturing fluid. They also noted that increasing of $\mathrm{Ba}$ concentration with time can be interpreted as a result of increased contact time and increased water-rock-ratio of later fluids.

It can be seen that, even though there is a general consensus in the observations reported from the field data, there is no consensus on the mechanisms behind those observations. Unlike the mechanisms proposed for laboratory observations, the theories proposed to explain the mechanisms behind field data lacks extensive research. For example, Renock et al. (2016) reported high Ba concentrations in the bulk samples from three Marcellus shale wells, whereas Zolfaghari et al. (2016) did not observe any Ba concentrations in bulk samples for three wells from Horn River Basin. As a result, the hypothesis by Zolfaghari et al. (2016) that Ba concentration observed in the flowback comes from the fracture network cannot be generalized. Therefore, in order to investigate 
the mechanisms behind field observations, we must i) increase the scale of experiment, and ii) test several samples from different shale plays.

\section{MECHANISMS OF WATER IMBIBITION IN SHALES}

Typically, the kerogen-rich shales are oil wet or mixed wet in nature (as discussed in section 3.2.1. Wettability), however, all the laboratory experiments report that the nonwetting aqueous fluid spontaneously imbibes into the shale samples. From a traditional definition of imbibition, we know that a non-wetting fluid cannot spontaneously imbibe into the pores of a rock just by capillary pressure itself, so there must be other mechanisms that drive the non-wetting fluid inside the shale rocks. Four mechanisms of fluid imbibition in shales have been proposed in the literature, which are: 1) capillary imbibition, 2) clay hydration, 3) osmosis, and 4) creation of micro-fractures. However, one mechanism that has not been discussed in the literature as a source of fracturing fluid loss is evaporation of water in shale. In this section, we will discuss these 5 mechanisms, including evaporation, and their working conditions.

\subsection{Capillary Imbibition}

The fluid interacts with the matrix in porous media through their wetting behavior, which is a function of interfacial physics between liquid and the solid. The spontaneous imbibition inside nanoscale pores is driven by the capillary pressure that acts on the meniscus formed between the wetting and non-wetting fluid and is also sometimes called Laplace pressure. As the wetting fluid moves inside the pores due to capillary pressure, it has to resist its own viscous force that is proportional to the invaded length of the wetting fluid. The motion of the fluid due to capillary force will stop once the increasing viscous force becomes equal to the capillary force. Other forces can also act on the invading fluid if the invading fluid is moving under gravity or if the capillary contains another fluid. Capillarity in conventional porous media has been covered extensively in the literature and for further discussions on this topic readers can refer other reviews (Alava et al. 2004; Kim and Kim 2013).

Small pore sizes and mineral heterogeneity in shales result in several transport mechanisms (Singh and Javadpour 2013; Singh et al. 2014; Singh and Javadpour 2016) that cannot be accounted solely by Darcy's law. In similar context, the typical behavior of capillary imbibition in shale cannot be explained solely by LW equation that describes the capillary filling in an ideal medium due to force balance between surface tension as a driving force and liquid viscosity as a resistive force. Capillary filling in shale deviates from ideal LW equation due to three factors: i) unconventional wettability that cannot be described by macroscopic contact angle, ii) spontaneous water uptake by mixed or oilwet shale, and iii) surface friction imposed on the liquid by the surfaces of the confined pore in shale. These three factors are discussed in detail below. 


\subsubsection{Wettability in shale}

Wettability of fluids in shale is expected to be significantly different from those in bulk phase (Evans 1990) that cannot be explained by traditional measurement of contact angle. Contact angle is a microscopic parameter, therefore, it is also sometimes called as the 'apparent contact angle' (Nosonovsky and Bhushan 2009), whereas, the actual angle under which the liquid-air interface touches the solid matrix at the micro- and nanometer scale can be different. Here, three reasons are provided to explain this behavior: 1) the water molecules form a thin layer on many solid surfaces because of disjoining pressure developed by a long-distance van der Waals adhesion force (Derjaguin and Churaev 1974). The magnitude of this disjoining pressure depends on the thickness of the liquid layer that could lead to formation of stable thin films that transforms the shape of the droplet from a sphere to a precursor layer, therefore producing a contact angle at the nanoscale that is much smaller than the 'apparent contact angle'. 2) water has a tendency to first fill hydrophilic areas with high surface energy and low contact angle (Checco et al. 2003), and the tilt in the angle due to rough surfaces can contribute to the 'apparent contact angle'. 3) As the liquid drop becomes smaller, the role of surface tension becomes less important compared to the line tension at the three-phase (liquid, air, solid) contact line (Marmur 1997; Yuan and Lee 2013), which can be curved for micro- and nanometer sized droplets (Blecua et al. 2006; Neumann et al. 2010).

To account for the discrepancy arising from contact angle measurement at the macroscale, the effect of line tension is added as a second term (Drelich 1996; Drelich et al. 1996; Gaydos and Neumann 1987) to obtain a correct contact angle $\left(\theta_{\text {corr }}\right)$ as shown in equation (1):

$$
\cos \left(\theta_{\text {corr }}\right)=\cos \left(\theta_{Y}\right)-\frac{\tau_{\text {sla }}}{\sigma_{l a} r_{d}}
$$

Where $\theta_{\text {corr }}$ is the corrected contact angle, $\theta_{Y}$ is the value of the contact angle given by Young-Laplace equation, $\sigma_{l a}$ is the interfacial tension between liquid and air, $r_{d}$ is the radius of the droplet, $\tau_{\text {sla }}$ is the three-phase contact line tension. Contact line tension is a constant value at a fixed temperature and solid-fluid interaction, and it can be determined using various methods available in the literature (Winkler et al. 2016; Liu et al. 2013; Hienola et al. 2007).

It can be seen from equation (1) that the corrected value of contact angle depends on the size of liquid droplet, and it plays a significant role in in the assessment of wettability at small scale. It has been shown (Sundberg et al. 2007) that if the radius of droplet is below $10 \mu \mathrm{m}$, the contact angles obtained are larger than the macroscopic contact angles, indicating a positive $\tau_{\text {sla }}$ from equation (1), whereas if the radius of droplet is greater than $10 \mu \mathrm{m}$ then the contact angles obtained are almost the same as the macroscopic contact angle.

The above discussion on wettability at nanoscale explains the reason why some authors (Ghanbari and Dehghanpour 2015; Xu and Dehghanpour 2014) observe contradictory results for wettability when measured using macroscopic contact angle and 
using length of liquid uptake, respectively. Therefore, contact angle measurement for wettability of shales must be carefully controlled by taking into account the size of the droplet as it plays a significant role in determining the true wettability. This can be achieved through existing methods (Contreras-Naranjo and Ugaz 2013) developed to interrogate the solid-fluid interaction at nanometer scale.

\subsubsection{Water uptake by oil/mixed-wet shales}

From our traditional understanding of imbibition in conventional rocks, we know that a non-wetting fluid cannot spontaneously imbibe into the pores of a rock. Typically, the kerogen-rich shales are oil-wet or mixed-wet in nature as discussed in the experimental observations, but all the laboratory experiments report that the non-wetting aqueous fluid spontaneously imbibes into the shale samples. This unconventional phenomenon of water uptake by oil-wet shales can be explained by a simple expression first proposed by Marmur (1988) that relates the drop radius $\left(r_{d}\right)$ with the radius of the capillary $\left(r_{c}\right)$ and the macroscopic contact angle $\left(\theta_{Y}\right)$ as follow:

$$
r_{d}<\frac{-r_{c}}{\cos \left(\theta_{Y}\right)}
$$

Therefore, it is possible for an oil/mixed-wet $\left(\theta_{Y} \geq 90^{\circ}\right)$ shale capillary to imbibe water if the above condition for the water droplet size is satisfied. This criteria proposed by Marmur (1988) has been tested experimentally (Willmott et al. 2011) and investigated for different shapes of capillaries (Marmur 1988b; Denesuk et al. 1993). This criteria has also found application in the field of carbon nanotubes as capillaries (Schebarchov and Hendy 2008a; Schebarchov and Hendy 2008b; Schebarchov and Hendy 2011).

Even though there is no experimental evidence yet to validate the above condition in shales, we hypothesize that the above condition is also satisfied in oil-wet or mixedwet shales that imbibe water spontaneously.

\subsubsection{Surface friction}

Although the concept of surface friction on liquid imbibition (often referred to as contact-line friction) has been studied for other mediums (Tenan et al. 1982; Hamraoui et al. 2000; Supple and Quirke 2004; Martic et al. 2005; Bertrand et al. 2009; Stukan et al. 2010) in the context of dynamic contact angle, it has not been considered as a parameter to describe the resistance to liquid flow in shale. The surface friction on imbibition dynamics in tight porous medium such as shales would typically develop due to roughness and confined nature of the pores. Even though there are different expressions for surface friction coefficient in the literature (Hamraoui et al. 2000; Supple and Quirke 2004; Bertrand et al. 2009), a closest expression that can account for the surface roughness and pore confinement was first proposed by Stukan et al. (2010) as shown below:

$$
\xi=\frac{\mu_{\text {bulk }}}{\rho_{\text {bulk }} \lambda^{3}} \exp \left[\frac{\gamma\left(1+\cos \theta_{e}\right) \lambda^{2}}{k_{B} T}\right]
$$


Where $\xi$ is the contact-line friction between the liquid-solid and has the same units as viscosity, $\mu_{\text {bulk }}$ is the bulk fluid viscosity, $\gamma$ is the surface tension between the wetting and non-wetting fluids, $\theta_{e}$ is the contact angle at equilibrium condition, $\lambda$ is the average length of the molecular displacement $(\sim$ of the order of the distance between the adsorption sites on the solid surface $\sim 0.95 \sigma), k_{B}$ is the Boltzmann's constant, and $T$ is the temperature.

Kelly et al. (2016) showed that surface induced solid-fluid interaction in nanoscale confinements leads to an increased viscosity compared to its bulk value. Therefore, we can account for surface friction by developing a simple expression for viscosity that accounts for surface friction in the imbibition dynamics as follow:

$$
\mu_{\text {eff }}=\mu_{\text {bulk }}+\xi=\mu_{\text {bulk }}\left\{1+\frac{1}{\rho_{\text {bulk }} \lambda^{3}} \exp \left[\frac{\gamma\left(1+\cos \theta_{e}\right) \lambda^{2}}{k_{B} T}\right]\right\}
$$

The effect of surface friction force on capillary imbibition can also be explained using the tangential momentum transferred by the liquid particles colliding with the wall as follow (Supple and Quirke 2004):

$$
F_{f}=\frac{N_{\text {coll }} m \Delta u_{w}}{\Delta t}
$$

Where $F_{f}$ is the force exerted by the surface friction on the liquid motion, $N_{\text {coll }}$ are the number of particle collisions with the solid wall in time $\Delta t, m$ is the mass of the particles colliding with the wall, and $\Delta u_{w}\left(=u_{o u t}-u_{\text {in }}\right)$ is the mean velocity change for the particles colliding with the wall. Further, this frictional force can be written as follow:

$$
F_{f}=\zeta v_{\text {avg }}
$$

Where, $\zeta$ is the surface friction coefficient and $v_{\text {avg }}$ is the average velocity of the bulk fluid.

\subsection{Clay Hydration}

Clays absorb water inside shale formations through development of an electrical potential gradient by the presence of a charged wall on clay particles. Based on the long history of research in colloid chemistry, it is known that the clay minerals act as semipermeable membranes and its interaction with aqueous solutions can generally be explained by the electrical double layer (EDL), which drives interaction between the clay minerals and aqueous solution inside the shale. According to the EDL concept, negatively charged clay surface is associated with two layers of hydrated cations. The first layer consists of hydrated cations that are attached firmly and closest to the negatively charged clay surface, and this layer is widely referred to as the Stern layer. Followed by the Stern layer, is a second layer that is diffusive in nature because of its gradually decreasing concentration away from the clay surface till the point where its concentration becomes equal to the cation concentration in the external bulk solution (Wilson et al. 2016). The characteristic thickness of the EDL is generally referred to as Debye length $\left(L_{D}\right)$, which represents the length over which the electrostatic effects persist. This phenomenon is illustrated schematically in Figure 6 that shows the charge distribution around clay surface and the concept of EDL. 


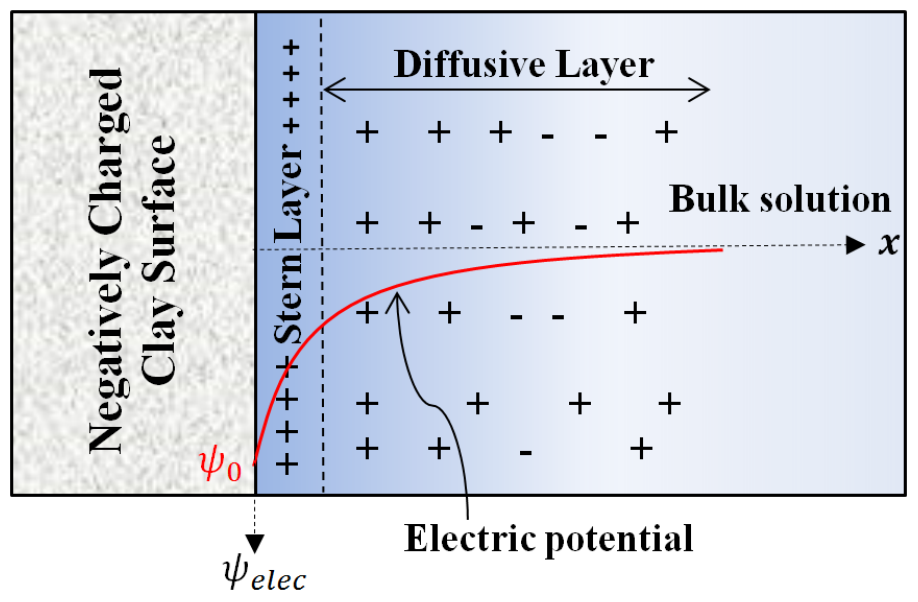

Figure 6: Schematic to depict the charge distribution around clay surface and to illustrate the general concept of EDL

The electric potential (or electric pressure) in the EDL $\left(=\psi_{\text {elec }}\right)$ is calculated using the Poisson and Boltzmann equations, and its approximate analytical solution is given (Eijkel and Berg 2010) as following:

$$
\begin{aligned}
& \psi_{\text {elec }}(x)=\psi_{0} \exp \left[\frac{-x}{L_{D}}\right] \\
& L_{D}=\left(\frac{\varepsilon R T}{F^{2} \sum_{i} C_{i} z_{i}^{2}}\right)
\end{aligned}
$$

Where $\psi_{\text {elec }}$ is electric potential in the EDL, $x$ is the distance away from the clay surface, $L_{D}(\mathrm{~m})$ is the Debye length, $\varepsilon\left(\mathrm{Fm}^{-1}\right)$ is the medium permittivity, $R$ is gas constant $(8.31 \mathrm{~J}$ $\left.\mathrm{mol}^{-1} \mathrm{~K}^{-1}\right), T$ is absolute temperature $(\mathrm{K}), F$ is the Faraday constant $\left(96485 \mathrm{C} \mathrm{mol}^{-1}\right), C_{i}$ is the molar concentration of solute ion $\mathrm{i}, z_{i}$ is the ionic charge number. Value of $L_{D}$ increases as the aqueous solution becomes more dilute, therefore, because of this reason we observe that clays swell more with clean water than with saline water. The swelling of clays can also be explained by osmosis, which is discussed in the next section.

Some authors (Roshan et al. 2016; Yang et al. 2016) reported that clays like smectite (particularly monmorillonite) and illite/smectite mixed-layer clay show significant swelling with water absorption, however, they did not mention the reason behind such observation. It is conjectured that this enhanced clay swelling is due to high external surface charge density of illite clays because of its exceedingly small particle size and high external surface area, which can be greater than the external surface area of smectite (Wilson et al. 2016). Because of this high external surface area in illite, the EDLs on opposing surfaces of illite are likely to overlap each other that could result in an increased repulsive force, and as a result an increase in pore pressure. The length of EDL can typically vary between few nanometers (Johnston and Tombacz 2002) to tens of nanometers (Tchistiakov 2000). For dilute solutions, it has been shown (Olphen 1963) that the length of EDL can be about $100 \mathrm{~nm}$ with monovalent cations and $50 \mathrm{~nm}$ with 
divalent cations. Therefore, it is likely that the thickness of EDL will exceed the pore sizes in shales, where $80 \%$ of pores are in the range of $2 \mathrm{~nm}$ to $15 \mathrm{~nm}$ (Katsube 1991; Katsube and Williamson 1994), and this may result in an increase in pore pressure.

\subsection{Osmosis}

Osmosis is a process by which a solvent passes through a semi-permeable membrane (like shale) from a region of low solute concentration (low salinity) to a region of high solute concentration (high salinity). The difference in solute concentration on two sides of the semi-permeable membrane creates a pressure gradient that moves the solvent as shown in Figure 7. Diffusion is a special case of osmosis, such that if no semipermeable membrane separates the two solutions with different concentrations, then the solute particles will diffuse until the solute concentration has equalized.

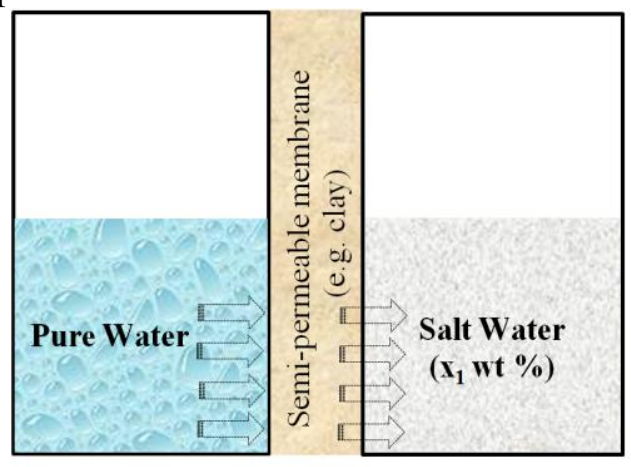

(a) Initial condition

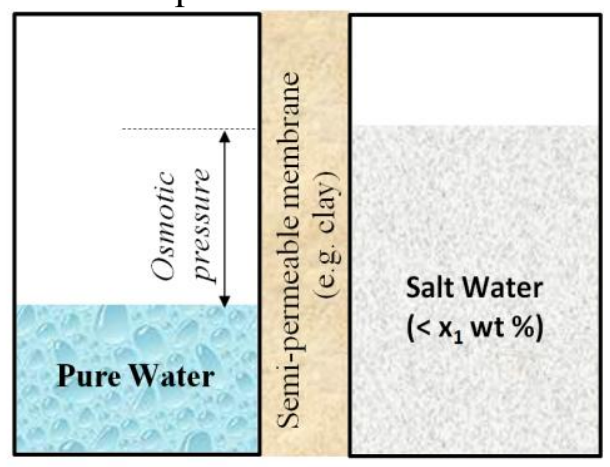

(b) Equilibrium condition

Figure 7: Schematic to illustrate osmosis, at a) initial condition, and b) equilibrium condition

The pressure gradient developed due to the difference in solute concentration can create high pressure anomalies in the geologic formations (Marine and Fritz 1981; Neuzil 2000; Neuzil and Provost 2009). For instance, a fracturing fluid with $1000 \mathrm{ppm}$ of salinity when injected into a shale reservoir containing 150,000 ppm of brine can develop an osmotic pressure as high as 2000 psi (Fakcharoenphol et al. 2016). Neuzil and Provost (2009) analyzed data from different clay-rich shale formations and reported that osmotic pressure in some formations with $\sim 0.1$ porosities may exceed $30 \mathrm{MPa}$ whereas for formations with $\sim 0.2$ porosities the osmotic pressure may exceed $10 \mathrm{MPa}$.

The pressure due to osmosis $\left(=\psi_{\text {osm }}\right.$, also referred to as osmotic potential $)$ can be calculated as following (Marine and Fritz 1981):

$$
\psi_{\text {osm }}=\frac{R T}{V_{w}} \ln \left(\frac{a_{1}}{a_{2}}\right)
$$

Where $V_{w}$ is the molar volume of water $\left(\mathrm{m}^{3} \mathrm{~mol}^{-1}\right)$, and $a_{1}, a_{2}$ are the water activity in the two aqueous solutions. The water activity is one for pure water at sea level and standard temperature and pressure. Water activity at any pressure and temperature can be calculated from an equation of state given by Helgeson et al. (1981). 
Even though pores in shale can act as semi-permeable membrane, they are not ideal as semi-permeable membrane and that can have an impact on the theoretical development of osmotic pressure. Typically, there are wide variety and size of pores in shale that can be described (Kuila and Prasad 2013) as macro-pores (> $1000 \mathrm{~nm}$ ), mesopores $(10-100 \mathrm{~nm})$, and nanopores $(<10 \mathrm{~nm})$. The semi-permeable property of each type of pore in shale is non-ideal and different, therefore, the osmotic pressure developed inside shale would always be below the theoretical limit. Schlemmer et al. (2002) estimated that membrane efficiencies of shales and mudrocks can range from $10 \%$ to 90 $\%$, whereas the experimental data analyzed by Neuzil and Provost (2009) for different clay formations suggest even lower membrane efficiency. Fakcharoenphol et al. (2014) suggested that because of these small membrane efficiencies, the pressures developed in the laboratory due to osmosis are not as high as the theoretical estimate of the osmotic pressure for an ideal membrane.

\subsection{Creation of Micro-fractures}

Based on the results reported by Makhanov (2013), it seems that swelling of clay is not the only mechanism that creates micro-fractures because some micro-fractures are also created with the imbibition of oil despite having no affinity for absorption in clays. Therefore, this suggests that some pore pressure is developed due to imbibition of fluid (water or oil) even without clay swelling inside the rock that initiates the creation of micro-fractures. The enhancement in pore pressure would be more substantial in presence of clay swelling, and that is the reason we see more micro-fractures with imbibition of water than with imbibition of oil as shown in Figure 2.

Özkaya (1988) proposed the following expression to describe the oil-induced fracturing in sedimentary rocks that can be used to describe the initiation of microfractures due to imbibition in shale:

$$
\Delta P_{\text {pore }}>\frac{S_{v}\left(2-\frac{S_{h}}{S_{v}}\right)+T}{2 A R-1}
$$

Where $\Delta P_{\text {pore }}$ is increase in pore pressure required to initiate micro-fracture in a shale rock, $S_{h}$ is the total minimum stress (or total horizontal stress), $S_{v}$ is the total maximum stress (or total vertical stress), $T$ is tensile stress, $A R$ is the aspect ratio of the pores in shale rock that is defined as the ratio of a pore's lengths along the two axes (for e.g. in an elliptical pore $A R$ would be the ratio of the major axis length to the minor axis length). In the above equation, it can be seen that the increase in pore pressure required to initiate a micro-fracture in shale has an inverse relationship with the aspect ratio or in other words the higher the aspect ratio of the pore, the lower the magnitude of pore pressure increase that would be required to initiate the micro-fracture. According to Lash and Engelder (2005), $\Delta P_{p}$ required to initiate micro-fracture in Dunkirk Shale in western New York can vary from 2.3 $\mathrm{MPa}$ to $16.5 \mathrm{MPa}$ for pores with an aspect ratio varying from 15 to 2.5 , respectively. 


\subsection{Evaporation}

Here, we provide three characteristics associated with shale formations that could facilitate evaporation of water: 1) gas expansion, 2) water droplets formed at asperities or cavities in fractures, and 3) pore confinement.

Evaporation due to gas expansion is evident based on past experimental studies (Kamath and Laroche 2003; Mahadevan and Sharma 2005) that showed gas expansion resulted in significant water evaporation. In the context of shale, Le et al. (2012) conducted experiments and simulations and they also reported evaporation of water while studying gas recovery. Evaporation of water due to gas expansion in the reservoir can be explained by the fact that the movement of gas assists in transferring water vapor from one region to another, just a dry wind facilitates evaporation from earth's surface. In the similar context, expanding gas inside the reservoir will leave a space of unsaturated volume where water will evaporate to saturate that space as vapors (Mills and Wells 1919). In field scenario, after shut-in period the produced gas coming from fractures towards the wellbore will undergo expansion, which would likely result in water evaporation over a long period of time. This phenomenon has been observed in terms of change in moisture content of a coal seam during coalbed methane extraction (Martin 1986; Plug et al. 2008; Su et al. 2008; Chen et al. 2012; Ibrahim and Nasr-El-Din 2015; Teng et al. 2016) and a production history from a field depicting this phenomenon is shown in Figure 8. This figure shows two periods of production denoted by 1 and 2 that represent the stages of liquid water flow and water vapor flow, respectively. The data from the field also illustrates that evaporation becomes more significant at late times, an observation that has been verified in laboratory (Mahadevan et al. 2006; Mahadevan et al. 2007) for tight gas reservoir rocks.

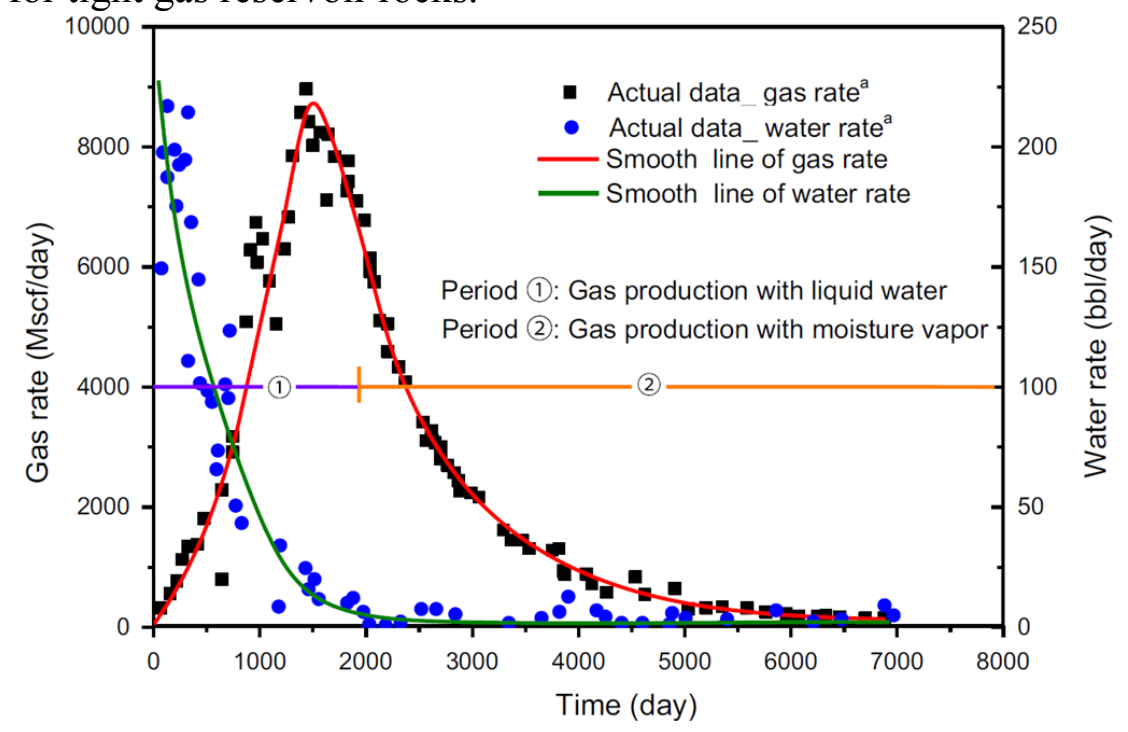

Figure 8: Production data from Fruitland formation showing gas production and water in two different stages (Teng et al. 2016; Ibrahim and Nasr-El-Din 2015) 
Fractures are an important characteristic of shale reservoirs that are required to make them economically productive. Evaporation of water from fractures is one of the possibility that has been studied in the past (Ho 1997) and also very recently in the context of coal seams (Teng et al. 2016). The seminal study by Ho (1997) hypothesized that the evaporation of pendant water droplets that are formed at asperities or cavities in fractures is possible even at nearly saturated environments. According to Ho (1997), effect of liquid-vapor meniscus on enhancing evaporation of water is significant only for small droplets $(<1 \mu \mathrm{m})$ and nearly saturated environment with close to $100 \%$ relative humidity. This condition is quite relevant in shale formations where $80 \%$ of the pores are in the range of $2 \mathrm{~nm}$ to $15 \mathrm{~nm}$ (Katsube 1991; Katsube and Williamson 1994), therefore, the water is likely to flow in small droplets in these pores.

Another factor that would favor water evaporation in shale is its confining nature as that would result in shifting the thermodynamic equilibrium due to high energy of small droplets. At thermodynamic equilibrium, the mean curvature of the liquid surface in contact with saturated vapor is zero, whereas a convex interface $(>0)$ results in evaporation over condensation. Therefore, small droplets that have convex meniscus and higher energy tend to evaporate (Nosonovsky and Bhushan 2009; Honschoten et al. 2010). Water droplets greater than $100 \mu \mathrm{m}$ behave similar to a flat surface of liquid (Ho 1997), while droplets smaller than this size tend to behave as discontinuous phase. Recently, Zhu et al. (2016) demonstrated how glycerol-water mixture breaks into smaller droplets as it moves through both expanding and contracting microcapillaries containing oil as the second phase (Figure 9). Creation of droplets in microcapillary has been covered extensively in a review by Baroud et al. (2010).
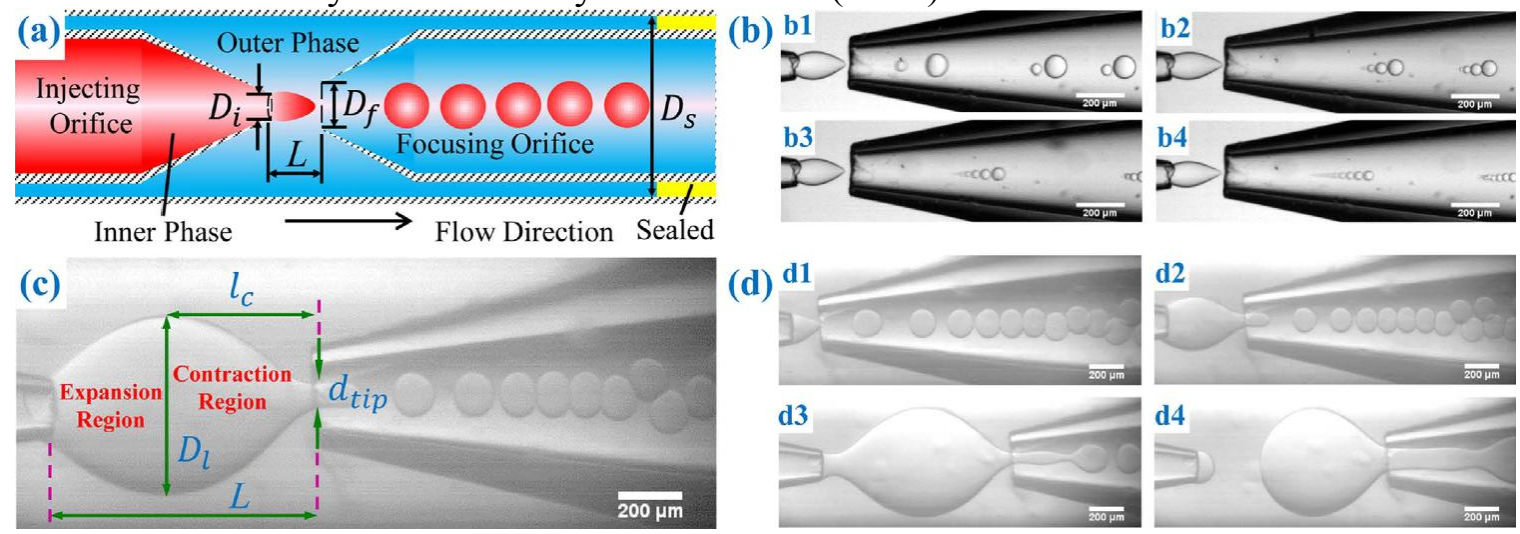

(d)
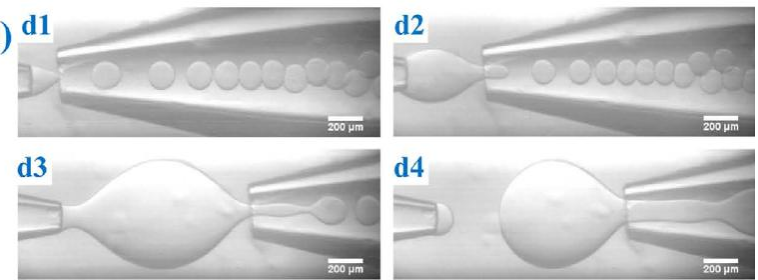

Figure 9: Influence of expanding-contracting microchannels on water droplet: a) schematic of microcapillary device (not on scale), b) droplets produced in sequence with decreasing size distribution 2, 4, 6, 8-drops, respectively. c) image of the expansioncontraction microchannel, and d) droplets produced with increasing orifice distance $L$ (from Zhu et al. 2016). 
In the absence of thermal gradients, the vapor pressure and meniscus curvature of the imbibing liquid in the pore space are related to each other through Kelvin equation (Glasstone 1946; Ward and Morrow 1987):

$$
r_{k}=\frac{\sigma_{L V} V_{a}}{R T} \ln \left(\frac{p_{s}}{p}\right)
$$

Where, $r_{k}$ is the Kelvin radius (radius of curvature of the meniscus obtained by Kelvin equation), $\sigma_{L V}$ is liquid-vapor surface tension, $V_{a}$ is the molar volume of air, $p_{s}$ is the saturation pressure, $p$ is the actual vapor pressure. Saturation pressure $\left(p_{s}\right)$ is the pressure at which partial pressure of vapor is at equilibrium with liquid water. The meniscus radius given by equation (11) must also satisfy the Young-Laplace equation $\left(P_{c a p}=\right.$ $\left.\sigma_{L V} / r_{k}\right)$, therefore, we get the following resultant equation:

$$
P_{\text {cap }}=\frac{R T}{V_{a}} \ln \left(\frac{p_{s}}{p}\right)
$$

The capillary pressure from above equation can be used to calculate the Laplace capillary force by multiplying it with the area of the meniscus. A convex interfacial meniscus with a positive curvature $\left(r_{k}>0\right)$ indicates higher pressure in the imbibing liquid that favors evaporation over condensation, whereas a concave interface with negative curvature $\left(r_{k}<0\right)$ indicates lower pressure in the imbibing liquid that favors condensation over evaporation. At thermodynamic equilibrium, the rate of evaporation and the rate of condensation are similar.

The evaporation of water from porous media works in two different stages (Philip 1957; Brakel 1980; Lehmann et al. 2008). During stage-1, the evaporation rate is constant and driven by transport of ions by convection towards the evaporation surface (Shokri et al. 2008), whereas the evaporation rate in stage- 2 is controlled by the diffusion of vapor from through the porous medium because the water becomes completely disconnected and forms isolated water clusters. The rate of evaporation of water in stage1 is defined by convective conditions whereas for stage- 2 it is defined by diffusionlimited conditions. In the context of flowback water from shale, stage 1 would be analogous to the flowback period while stage 2 would be analogous to the period after well shut-in. The time required for the onset of brine evaporation (or salt precipitation) inside the shale reservoir can be estimated using the convection-diffusion equation that defines the transport of a species inside a porous media as follow:

$$
\frac{\partial\left(\phi \rho S_{w} C\right)}{\partial t}=\frac{\partial}{\partial x}\left(\rho \phi S_{w} D \frac{\partial C}{\partial z}\right)-\frac{\partial\left(\rho \phi S_{w} C v_{\text {avg }}\right)}{\partial x}
$$

Where $\rho$ is the liquid density, $S_{w}$ is the water saturation, $\phi$ is the medium porosity, $C$ is the salt concentration in the brine, $D$ is the diffusion constant for the salt, $v_{\text {avg }}$ is the average velocity of the brine, and $x$ is the direction of fluid movement. If we assume a constant evaporation rate $E$ (mass per unit area per time), water saturation that changes with time $t$, then we have the following (Guglielmini et al. 2008):

$$
\begin{aligned}
& E=-\rho L \phi\left(\frac{d S_{w}}{d t}\right) \\
& S_{w}=1-\left(\frac{E}{\rho L \phi}\right) t
\end{aligned}
$$


Using mass balance for the liquid, we have (Huinink et al. 2002):

$v_{\text {avg }}=\frac{E}{\rho L \phi S_{w}(t)}(x-L)$

(16)

Where $L$ is the length of the medium.

\section{Simulation of Spontaneous Imbibition in Shales}

Several authors have tried to simulate the behavior of liquid imbibition in shales or other nano-sized pores and capillaries. Their general approach is to modify the pressure or force equation by combining the contribution from individual mechanism driving the imbibition. Seven models with varying level of complexity that can be applied to model the behavior of liquid imbibition in shale are reviewed. Even though there is no model yet in the literature that accounts for all the 5 mechanisms discussed earlier, seven models can partially account for the composite mechanisms responsible for liquid uptake in shale. We review the principle behind each model followed by a table summarizing the capability of each model in terms of imbibition mechanisms considered.

Supple and Quirke (2004) proposed a model to estimate the length of capillary filling in nanotubes by including the effect of capillary forces and surface friction. The surface friction imposed by the solid wall on the liquid motion is fundamental to the accuracy of their model. Even though their model is not specifically meant for shales, their idea of relating the liquid filling and its speed to the solid-fluid surface tensions (capillarity) and interfacial friction between the imbibing liquid and the solid surface is equally important for the liquid imbibition in shales. Stukan et al. (2010) investigated the effect of micro-scale wettability and surface roughness in nanopores on the imbibition of liquid using molecular dynamics (MD) simulations. The micro-scale wettability, defined by the dynamic contact angle, was described using the molecular-kinetics theory. Cai and $\mathrm{Yu}$ (2011) proposed a model to provide a solution to many experimental results from porous media, including clay rich media that don't obey the $t^{0.5}$ rule by formulating a variable exponent in terms of the fractal dimension for tortuosity of capillaries. Liu et al. (2015) developed a semi-analytical model to capture the imbibition behavior in shales by assuming the liquid flux as a power function of capillary pressure gradient. Binazadeh et al. (2016) accounted for the effect of clay hydration by considering electrostatic interaction theory. Kiepsch and Pelster (2016) considered the effect of evaporation and the adsorption of evaporated molecules on the walls of synthetic media composed of nano-sized pores. Wang and Rahman (2016) included the effect of osmosis and the creation of micro-fractures using a numerical model. 
Table 2: Imbibition models for shale with their corresponding mechanisms

\begin{tabular}{|c|c|c|c|c|c|c|c|}
\hline \multirow[b]{3}{*}{ Model } & \multicolumn{7}{|c|}{ Imbibition Mechanisms in Shale } \\
\hline & \multicolumn{3}{|c|}{ Capillary } & \multirow[b]{2}{*}{$\begin{array}{c}\text { Clay } \\
\text { hydration }\end{array}$} & \multirow[b]{2}{*}{ Osmosis } & \multirow[b]{2}{*}{$\begin{array}{l}\text { Micro- } \\
\text { fractures }\end{array}$} & \multirow[b]{2}{*}{ Evaporation } \\
\hline & $\begin{array}{c}\text { Surface } \\
\text { tension and } \\
\text { viscous } \\
\text { forces }\end{array}$ & $\begin{array}{c}\text { Micro-scale } \\
\text { wettability }\end{array}$ & $\begin{array}{l}\text { Surface } \\
\text { friction }\end{array}$ & & & & \\
\hline $\begin{array}{c}\text { Supple and } \\
\text { Quirke (2004) }\end{array}$ & $\mathrm{x}$ & & $\mathrm{x}$ & & & & \\
\hline $\begin{array}{c}\text { Stukan et al. } \\
(2010)\end{array}$ & $\mathrm{x}$ & $\mathrm{x}$ & $\mathrm{x}$ & & & & \\
\hline $\begin{array}{c}\text { Cai and Yu } \\
\text { (2011) }\end{array}$ & $\mathrm{x}$ & & & & & & \\
\hline Liu et al. (2015) & $\mathrm{x}$ & & & & & & \\
\hline $\begin{array}{c}\text { Binazadeh et al. } \\
(2016)\end{array}$ & $\mathrm{x}$ & & & $\mathrm{x}$ & & & \\
\hline $\begin{array}{c}\text { Kiepsch and } \\
\text { Pelster }(2016)\end{array}$ & $\mathrm{x}$ & & & & & & $\mathrm{x}$ \\
\hline $\begin{array}{c}\text { Wang and } \\
\text { Rahman (2016) }\end{array}$ & $\mathrm{x}$ & & & & $\mathrm{x}$ & $\mathrm{x}$ & \\
\hline
\end{tabular}

Even though there is a constant effort by many researchers in understanding the imbibition behavior through laboratory experiments, there is a clear gap in mimicking those laboratory observations through a comprehensive model. It can be seen from above table that there is no single model that can mimic all the processes of imbibition in shale. Also, it must be noted that not all the listed models were proposed to simulate the general imbibition behavior in shale as some of them were used to solve a different problem, but they are useful to investigate the composite mechanisms of imbibition in shale.

\section{Concluding Remarks and Future Directions}

Many laboratory experiments have been conducted to report observations for liquid imbibition in shales from different part of the world, and for the most part there is consistency in observations reported by most of the authors. From the laboratory observations reported in the literature, many different mechanisms seem to be facilitating imbibition in the shale. However, all those mechanisms should not be expected to be contributing in the retention of fracturing fluid in the field, because typically the experiments in laboratory are conducted under unconfined conditions and without a second liquid phase such as hydrocarbon or basin brine. At this point it cannot be said how these two factors may impact the fracturing fluid loss in the field, but it is safe to assume that confining pressure will have an impact on the creation of micro-fractures, and swelling of clay, two commonly reported laboratory observations. 
From the above discussions, it can be seen that we do not yet have an answer for mechanisms behind some of the common phenomena reported by majority of the authors. In particular, these include: i) mechanism behind creation of micro-fractures, ii) why the permeability of fractures decreases, while the permeability of micro-fractures increases, iii) why the growth of imbibition length with time shows an inconsistent pattern across different shales. Although many mechanisms seem to be contributing to liquid filling in shale, there is no consensus on the dominant mechanisms. Wettability is one of the fundamental properties that control imbibition due to capillary suction, and in this regard we explained why the macroscopic contact angle measurement is not adequate to determine wettability of shales. A modified contact angle measurement method that accounts for fluid-solid interaction in nanometer sized pores of shale rock was suggested.

Even though some observations from field provide consistent signatures, we do not yet have a verified answer for the geo-mechanisms behind those observations. Mainly, it is because of the various coupled processes happening in the reservoir that it is extremely difficult to investigate them experimentally, but, to some extent it is also because of the variability in mineralogy, such as $\mathrm{Ba}$, across shales which cannot be captured within the scale of laboratory experiments as discussed in the context of Zolfaghari et al. (2016) and Renock et al. (2016).

Loss of massive amount of fracturing water inside shale formations not only ruins the productivity of a reservoir, but it also puts pressure on areas with scarce water resources by depriving huge amount of water that could be reused. Therefore, research efforts to improve our understanding of what causes an enormous amount of water loss inside shale reservoir will continue.

\section{ACKNOWLEDGMENT}

This research was supported in part by an appointment to the National Energy Technology Laboratory Research Participation Program, sponsored by the U.S. Department of Energy and administered by the Oak Ridge Institute for Science and Education.

\section{REFERENCES}

Alava, Mikko, Martin Dubé, and Martin Rost. 2004. "Imbibition in Disordered Media." Advances in Physics 53 (2): 83-175. doi:10.1080/00018730410001687363.

Bakli, Chirodeep, and Suman Chakraborty. 2012. "Capillary Filling Dynamics of Water in Nanopores." Applied Physics Letters $101 \quad$ (15): 153112. doi: $10.1063 / 1.4758683$.

Bell, J. M., and F. K. Cameron. 1905. "The Flow of Liquids through Capillary Spaces." The Journal of Physical Chemistry 10 (8): 658-74. doi:10.1021/j150080a005.

Bertrand, Emilie, Terence D. Blake, and Jo?1 De Coninck. 2009. "Influence of Solid?liquid Interactions on Dynamic Wetting: A Molecular Dynamics Study." Journal of Physics: Condensed Matter 21 (46): 464124. doi:10.1088/09538984/21/46/464124. 
Binazadeh, Mojtaba, Mingxiang Xu, Ashkan Zolfaghari, and Hassan Dehghanpour. 2016. "Effect of Electrostatic Interactions on Water Uptake of Gas Shales: The Interplay of Solution Ionic Strength and Electrostatic Double Layer." Energy \& Fuels 30 (2): 992-1001. doi:10.1021/acs.energyfuels.5b02990.

Blauch, Matthew Eric, Roger R. Myers, Tom Moore, Brian Andrew Lipinski, and Nathan Allan Houston. 2009. "Marcellus Shale Post-Frac Flowback Waters - Where Is All the Salt Coming from and What Are the Implications?" In . Society of Petroleum Engineers. doi:10.2118/125740-MS.

Blecua, Pedro, Reinhard Lipowsky, and Jan Kierfeld. 2006. "Line Tension Effects for Liquid Droplets on Circular Surface Domains." Langmuir 22 (26): 11041-59. doi:10.1021/la0609773.

Borysenko, Artem, Ben Clennell, Rossen Sedev, Iko Burgar, John Ralston, Mark Raven, David Dewhurst, and Keyu Liu. 2009. "Experimental Investigations of the Wettability of Clays and Shales." Journal of Geophysical Research: Solid Earth 114 (B7): B07202. doi:10.1029/2008JB005928.

Brakel, J. Van. 1980. "Mass Transfer in Convective Drying." ResearchGate 1: 217-67.

Cai, Jianchao, Xiangyun Hu, Dag Chun Standnes, and Lijun You. 2012. "An Analytical Model for Spontaneous Imbibition in Fractal Porous Media Including Gravity." Colloids and Surfaces A: Physicochemical and Engineering Aspects 414: 228233.

Cai, Jianchao, Edmund Perfect, Chu-Lin Cheng, and Xiangyun Hu. 2014. "Generalized Modeling of Spontaneous Imbibition Based on Hagen-Poiseuille Flow in Tortuous Capillaries with Variably Shaped Apertures." Langmuir 30 (18): 514251. doi:10.1021/la5007204.

Cai, Jianchao, and Boming Yu. 2011. "A Discussion of the Effect of Tortuosity on the Capillary Imbibition in Porous Media." Transport in Porous Media 89 (2): 25163. doi:10.1007/s11242-011-9767-0.

Cai, Jianchao, Boming Yu, Mingqing Zou, and Liang Luo. 2010. "Fractal Characterization of Spontaneous Co-Current Imbibition in Porous Media." Energy \& Fuels 24 (3): 1860-1867.

Capo, Rosemary C., Brian W. Stewart, Elisabeth L. Rowan, Courtney A. Kolesar Kohl, Andrew J. Wall, Elizabeth C. Chapman, Richard W. Hammack, and Karl T. Schroeder. 2014. "The Strontium Isotopic Evolution of Marcellus Formation Produced Waters, Southwestern Pennsylvania." International Journal of Coal Geology, Environmental geology and the unconventional gas revolution, 126 (June): 57-63. doi:10.1016/j.coal.2013.12.010.

Checco, Antonio, Patrick Guenoun, and Jean Daillant. 2003. "Nonlinear Dependence of the Contact Angle of Nanodroplets on Contact Line Curvature." Physical Review Letters 91 (18): 186101. doi:10.1103/PhysRevLett.91.186101.

Chen, Dong, Zhejun Pan, Jishan Liu, and Luke D. Connell. 2012. "Modeling and Simulation of Moisture Effect on Gas Storage and Transport in Coal Seams." Energy \& Fuels 26 (3): 1695-1706. doi:10.1021/ef2014327. 
Cheng, Yueming. 2012. "Impact of Water Dynamics in Fractures on the Performance of Hydraulically Fractured Wells in Gas-Shale Reservoirs." Journal of Canadian Petroleum Technology 51 (2): 143-51. doi:10.2118/127863-PA.

Chermak, John A., and Madeline E. Schreiber. 2014. "Mineralogy and Trace Element Geochemistry of Gas Shales in the United States: Environmental Implications." International Journal of Coal Geology, Environmental geology and the unconventional gas revolution, 126 (June): 32-44. doi:10.1016/j.coal.2013.12.005.

Contreras-Naranjo, Jose C., and Victor M. Ugaz. 2013. "A Nanometre-Scale Resolution Interference-Based Probe of Interfacial Phenomena between Microscopic Objects and Surfaces." Nature Communications 4 (May): 1919. doi:10.1038/ncomms2865.

Dehghanpour, H., Q. Lan, Y. Saeed, H. Fei, and Z. Qi. 2013. "Spontaneous Imbibition of Brine and Oil in Gas Shales: Effect of Water Adsorption and Resulting Microfractures." Energy \& Fuels 27 (6): 3039-49. doi:10.1021/ef4002814.

Dehghanpour, H., H. A. Zubair, A. Chhabra, and A. Ullah. 2012. "Liquid Intake of Organic Shales." Energy \& Fuels 26 (9): 5750-58. doi:10.1021/ef3009794.

Denesuk, M., G. L. Smith, B. J. J. Zelinski, N. J. Kreidl, and D. R. Uhlmann. 1993. "Capillary Penetration of Liquid Droplets into Porous Materials." Journal of Colloid and Interface Science 158 (1): 114-20. doi:10.1006/jcis.1993.1235.

Derjaguin, B. V, and N. V Churaev. 1974. "Structural Component of Disjoining Pressure." Journal of Colloid and Interface Science 49 (2): 249-55. doi:10.1016/0021-9797(74)90358-0.

Drelich, Jaroslaw. 1996. "The Significance and Magnitude of the Line Tension in ThreePhase (Solid-Liquid-Fluid) Systems." Colloids and Surfaces A: Physicochemical and Engineering Aspects 116 (1): 43-54.

Drelich, Jaroslaw, Jan D. Miller, and Robert J. Good. 1996. "The Effect of Drop (Bubble) Size on Advancing and Receding Contact Angles for Heterogeneous and Rough Solid Surfaces as Observed with Sessile-Drop and Captive-Bubble Techniques." Journal of Colloid and Interface Science 179 (1): 37-50.

Dutta, Riteja, Chung-hao Lee, Sijuola Odumabo, Peng Ye, Stacey C. Walker, Zuleima T. Karpyn, and Luis Felipe Ayala. 2012. "Quantification of Fracturing Fluid Migration due to Spontaneous Imbibition in Fractured Tight Formations." In . Society of Petroleum Engineers. doi:10.2118/154939-MS.

Ehlig-Economides, Christine A., and Michael John Economides. 2011. "Water As Proppant." In . Society of Petroleum Engineers. doi:10.2118/147603-MS.

Eijkel, Jan C. T., and Albert van den Berg. 2010. "Nanofluidics and the Chemical Potential Applied to Solvent and Solute Transport." Chemical Society Reviews 39 (3): 957-73. doi:10.1039/B913776A.

Evans, R. 1990. "Fluids Adsorbed in Narrow Pores: Phase Equilibria and Structure." Journal of Physics: Condensed Matter 2 (46): 8989. doi:10.1088/0953$8984 / 2 / 46 / 001$. 
Ezulike, D. O., O. A. Adefidipe, Y. Fu, H. Dehghanpour, C. J. Virues, D. Bearinger, R. V. Hawkes, and R. Steve Jones. 2015. "Flowback Fracture Closure: A Key Factor for Estimating Effective Pore-Volume." In . Society of Petroleum Engineers. doi:10.2118/175143-MS.

Fakcharoenphol, Perapon, Basak Kurtoglu, Hossein Kazemi, Sarinya Charoenwongsa, and Yu-Shu Wu. 2014. "The Effect of Osmotic Pressure on Improve Oil Recovery from Fractured Shale Formations.” In . Society of Petroleum Engineers. doi:10.2118/168998-MS.

Fakcharoenphol, Perapon, Basak Kurtoglu, Hossein Kazemi, Sarinya Charoenwongsa, and Yu-Shu Wu. 2015. "The Effect of Chemical Osmosis on Oil and Gas Production from Fractured Shale Formations." In Fluid Dynamics in Complex Fractured-Porous Systems, edited by Boris Faybishenko, Sally M. Benson, and John E. Gale, 85-97. John Wiley \& Sons, Inc. http://onlinelibrary.wiley.com/doi/10.1002/9781118877517.ch6/summary.

Fakcharoenphol, Perapon, Mehmet Torcuk, Hossein Kazemi, and Yu-Shu Wu. 2016. "Effect of Shut-in Time on Gas Flow Rate in Hydraulic Fractured Shale Reservoirs." Journal of Natural Gas Science and Engineering 32 (May): 109-21. doi:10.1016/j.jngse.2016.03.068.

Fan, Li, John Webster Thompson, and John R. Robinson. 2010. "Understanding Gas Production Mechanism and Effectiveness of Well Stimulation in the Haynesville Shale Through Reservoir Simulation." In . Society of Petroleum Engineers. doi:10.2118/136696-MS.

Gale, Julia F. W., Stephen E. Laubach, Jon E. Olson, Peter Eichhubl, and András Fall. 2014. "Natural Fractures in Shale: A Review and New Observations." $A A P G$ Bulletin 98 (11): 2165-2216. doi:10.1306/08121413151.

Gaydos, J, and A. W Neumann. 1987. "The Dependence of Contact Angles on Drop Size and Line Tension." Journal of Colloid and Interface Science 120 (1): 76-86. doi:10.1016/0021-9797(87)90324-9.

Gdanski, Rick D., Dwight D. Fulton, and Chun Shen. 2009. "Fracture-Face-Skin Evolution During Cleanup." SPE Production \& Operations 24 (1): 22-34. doi:10.2118/101083-PA.

Ge, Hong-Kui, Liu Yang, Ying-Hao Shen, Kai Ren, Fan-Bao Meng, Wen-Ming Ji, and Shan Wu. 2015. "Experimental Investigation of Shale Imbibition Capacity and the Factors Influencing Loss of Hydraulic Fracturing Fluids.” Petroleum Science 12 (4): 636-50. doi:10.1007/s12182-015-0049-2.

Ghanbari, Ebrahim, Majid Ali Abbasi, Hassan Dehghanpour, and Doug Bearinger. 2013. "Flowback Volumetric and Chemical Analysis for Evaluating Load Recovery and Its Impact on Early-Time Production." In . Society of Petroleum Engineers. doi:10.2118/167165-MS.

Ghanbari, Ebrahim, and Hassan Dehghanpour. 2015. "Impact of Rock Fabric on Water Imbibition and Salt Diffusion in Gas Shales." International Journal of Coal Geology 138 (January): 55-67. doi:10.1016/j.coal.2014.11.003. 
Glasstone, Samuel. 1946. Textbook of Physical Chemistry. D. Van Nostrand company, inc.

Gray, George Robert, Henry C. H. Darley, and Walter Francis Rogers. 1980. Composition and Properties of Oil Well Drilling Fluids. Gulf Publishing Company, Book Division.

Guglielmini, Laura, Alexandre Gontcharov, Antonio J. Aldykiewicz Jr, and Howard A. Stone. 2008. "Drying of Salt Solutions in Porous Materials: Intermediate-Time Dynamics and Efflorescence." Physics of Fluids (1994-Present) 20 (7): 77101. doi:10.1063/1.2954037.

Haluszczak, Lara O., Arthur W. Rose, and Lee R. Kump. 2013. "Geochemical Evaluation of Flowback Brine from Marcellus Gas Wells in Pennsylvania, USA.” Applied Geochemistry 28 (January): 55-61. doi:10.1016/j.apgeochem.2012.10.002.

Hamraoui, Ahmed, Krister Thuresson, Tommy Nylander, and Vassili Yaminsky. 2000. "Can a Dynamic Contact Angle Be Understood in Terms of a Friction Coefficient?" Journal of Colloid and Interface Science 226 (2): 199-204. doi:10.1006/jcis.2000.6830.

Handy, L. L. 1960. "Determination of Effective Capillary Pressures for Porous Media from Imbibition Data," January. https://www.onepetro.org/general/SPE-1361-G.

Helgeson, Harold C., David H. Kirkham, and George C. Flowers. 1981. "Theoretical Prediction of the Thermodynamic Behavior of Aqueous Electrolytes by High Pressures and Temperatures; IV, Calculation of Activity Coefficients, Osmotic Coefficients, and Apparent Molal and Standard and Relative Partial Molal Properties to 600 Degrees C and 5kb." American Journal of Science 281 (10): 1249-1516. doi:10.2475/ajs.281.10.1249.

Hienola, A. I., P. M. Winkler, P. E. Wagner, H. Vehkamäki, A. Lauri, I. Napari, and M. Kulmala. 2007. "Estimation of Line Tension and Contact Angle from Heterogeneous Nucleation Experimental Data." The Journal of Chemical Physics 126 (9): 94705. doi:10.1063/1.2565769.

Ho, Clifford K. 1997. "Evaporation of Pendant Water Droplets in Fractures." Water Resources Research 33 (12): 2665-71. doi:10.1029/97WR02489.

Honschoten, Joost W. van, Nataliya Brunets, and Niels R. Tas. 2010. "Capillarity at the Nanoscale." Chemical Society Reviews 39 (3): 1096-1114. doi:10.1039/B909101G.

Hu, Qinhong, Robert P. Ewing, and Stefan Dultz. 2012. "Low Pore Connectivity in Natural Rock." Journal of Contaminant Hydrology 133 (May): 76-83. doi:10.1016/j.jconhyd.2012.03.006.

$\mathrm{Hu}$, Qinhong, Robert P. Ewing, and Harold D. Rowe. 2015. "Low Nanopore Connectivity Limits Gas Production in Barnett Formation." Journal of Geophysical Research: Solid Earth 120 (12): $2015 J \mathrm{JB} 012103$. doi:10.1002/2015JB012103.

Hu, Qin-Hong, Xian-Guo Liu, Zhi-Ye Gao, Shu-Gen Liu, Wen Zhou, and Wen-Xuan Hu. 2015. "Pore Structure and Tracer Migration Behavior of Typical American and 
Chinese Shales." Petroleum Science 12 (4): 651-63. doi:10.1007/s12182-0150051-8.

$\mathrm{Hu}$, and Ewing. 2014. "Integrated Experimental and Modeling Approaches to Studying the Fracture-Matrix Interaction in Gas Recovery from Barnett Shale." 9122-12. University of Texas at Arlington.

Huber, Patrick. 2015. "Soft Matter in Hard Confinement: Phase Transition Thermodynamics, Structure, Texture, Diffusion and Flow in Nanoporous Media." Journal of Physics: Condensed Matter 27 (10): 103102. doi:10.1088/09538984/27/10/103102.

Huinink, H. P., L. Pel, and M. a. J. Michels. 2002. "How Ions Distribute in a Drying Porous Medium: A Simple Model." Physics of Fluids (1994-Present) 14 (4): 1389-95. doi:10.1063/1.1451081.

Ibrahim, Ahmed Farid, and Hisham A. Nasr-El-Din. 2015. "A Comprehensive Model to History Match and Predict Gas/water Production from Coal Seams." International Journal of Coal Geology 146 (July): 79-90. doi:10.1016/j.coal.2015.05.004.

Jiang, Xi. 2013. "Flowback Quality Characterization for Horizontal Wells in Wattenberg Field." Thesis, Colorado State University. Libraries. https://dspace.library.colostate.edu:443/handle/10217/81030.

Johnston, C. T., and E. Tombacz. 2002. "Surface Chemistry of Soil Minerals. Pp. 37Ā67 in: Soil Mineralogy with Environmental Applications (JB Dixon \& DG Schulze, Editors)." Soil Science Society of America, Madison, Wisconsin, USA.

Josh, M., L. Esteban, C. Delle Piane, J. Sarout, D. N. Dewhurst, and M. B. Clennell. 2012. "Laboratory Characterisation of Shale Properties." Journal of Petroleum Science and Engineering, Unconventional hydrocarbons exploration and production Challenges, 88-89 (June): 107-24. doi:10.1016/j.petrol.2012.01.023.

Kamath, Jairam, and Catherine Laroche. 2003. "Laboratory-Based Evaluation of Gas Well Deliverability Loss Caused by Water Blocking." SPE Journal 8 (1): 71-80. doi:10.2118/83659-PA.

Kanfar, Mohammed S., and Christopher R. Clarkson. 2016. "Reconciling Flowback and Production Data: A Novel History Matching Approach for Liquid Rich Shale Wells." Journal of Natural Gas Science and Engineering. Accessed May 27. doi:10.1016/j.jngse.2016.04.042.

Katsube, T. J. 1991. "Petrophysical Characteristics of Shales from the Scotian Shelf." Geophysics 56 (October): 1681-89. doi:10.1190/1.1442980.

Katsube, T. J., and M. A. Williamson. 1994. "Effects of Diagenesis on Shale Nano-Pore Structure and Implications for Sealing Capacity." Clay Minerals 29 (4): 451-61.

Kelly, Shaina, Carlos Torres-Verdín, and Matthew T. Balhoff. 2016. "Anomalous Liquid Imbibition at the Nanoscale: The Critical Role of Interfacial Deformations." Nanoscale 8 (5): 2751-67. doi:10.1039/C5NR04462F.

Kiepsch, Sebastian, and Rolf Pelster. 2016. "Interplay of Vapor Adsorption and Liquid Imbibition in Nanoporous Vycor Glass." Physical Review E 93 (4): 43128. doi:10.1103/PhysRevE.93.043128. 
Kim, Jungchul, and Ho-Young Kim. 2013. "On the Dynamics of Capillary Imbibition." Journal of Mechanical Science and Technology 26 (12): 3795-3801. doi:10.1007/s12206-012-1006-2.

Ksiezniak, Katarzyna, Rogala, Andrzej, and Hupka, Jan. 2015. "Wettability of Shale Rock as an Indicator of Fracturing Fluid Composition." doi:10.5277/ppmp150128.

Kuila, Utpalendu, and Manika Prasad. 2013. "Specific Surface Area and Pore-Size Distribution in Clays and Shales." Geophysical Prospecting 61 (2): 341-62. doi:10.1111/1365-2478.12028.

Lan, Qing, Ebrahim Ghanbari, Hassan Dehghanpour, and Robert Hawkes. 2014. "Water Loss Versus Soaking Time: Spontaneous Imbibition in Tight Rocks." Energy Technology 2 (12): 1033-39. doi:10.1002/ente.201402039.

Lan, Qing, Mingxiang Xu, Mojtaba Binazadeh, Hassan Dehghanpour, and James M. Wood. 2015. "A Comparative Investigation of Shale Wettability: The Significance of Pore Connectivity." Journal of Natural Gas Science and Engineering 27, Part 2 (November): 1174-88. doi:10.1016/j.jngse.2015.09.064.

Lash, Gary G., and Terry Engelder. 2005. "An Analysis of Horizontal Microcracking during Catagenesis: Example from the Catskill Delta Complex." AAPG Bulletin 89 (11): 1433-49. doi:10.1306/05250504141.

Le, Duc H., Hai N. Hoang, and Jagannathan Mahadevan. 2012. "Gas Recovery From Tight Sands: Impact of Capillarity." SPE Journal 17 (4): 981-91. doi:10.2118/119585-PA.

Lehmann, Peter, Shmuel Assouline, and Dani Or. 2008. "Characteristic Lengths Affecting Evaporative Drying of Porous Media." Physical Review E 77 (5): 56309. doi:10.1103/PhysRevE.77.056309.

Li, Dongqing. 2008. Encyclopedia of Microfluidics and Nanofluidics. Springer Science \& Business Media.

Liang, Lixi, Danxu Luo, Xiangjun Liu, and Jian Xiong. 2016. "Experimental Study on the Wettability and Adsorption Characteristics of Longmaxi Formation Shale in the Sichuan Basin, China." Journal of Natural Gas Science and Engineering. Accessed May 26. doi:10.1016/j.jngse.2016.05.024.

Liu, Hui-Hai, Bitao Lai, and Jinhong Chen. 2015. "Unconventional Spontaneous Imbibition into Shale Matrix: Theory and a Methodology to Determine Relevant Parameters." Transport in Porous Media 111 (1): 41-57. doi:10.1007/s11242015-0580-z.

Liu, Yawei, Jianjun Wang, and Xianren Zhang. 2013. "Accurate Determination of the Vapor-Liquid-Solid Contact Line Tension and the Viability of Young Equation." Scientific Reports 3 (June). doi:10.1038/srep02008.

Loucks, Robert G., Robert M. Reed, Stephen C. Ruppel, and Ursula Hammes. 2012. "Spectrum of Pore Types and Networks in Mudrocks and a Descriptive Classification for Matrix-Related Mudrock Pores." AAPG Bulletin 96 (6): 107198. doi:10.1306/08171111061. 
Lucas, Richard. 1918. "Ueber das Zeitgesetz des kapillaren Aufstiegs von Flüssigkeiten.” Kolloid-Zeitschrift 23 (1): 15-22. doi:10.1007/BF01461107.

Mahadevan, Jagannathan, and Mukul M. Sharma. 2005. "Factors Affecting Clean-up of Water-Blocks: A Laboratory Investigation.” SPE Journal 10 (3): 238-46. doi:10.2118/84216-PA.

Mahadevan, Jagannathan, Mukul Mani Sharma, and Yannis C. Yortsos. 2007. "Capillary Wicking in Gas Wells." SPE Journal 12 (4): 429-37. doi:10.2118/103229-PA.

Mahadevan, Jagannathan, Mukul M. Sharma, and Yannis C. Yortsos. 2006. "Flowthrough Drying of Porous Media." AIChE Journal 52 (7): 2367-80. doi:10.1002/aic.10859.

Makhanov, K., A. Habibi, H. Dehghanpour, and E. Kuru. 2014. "Liquid Uptake of Gas Shales: A Workflow to Estimate Water Loss during Shut-in Periods after Fracturing Operations." Journal of Unconventional Oil and Gas Resources 7 (September): 22-32. doi:10.1016/j.juogr.2014.04.001.

Makhanov, Kaiyrzhan. 2013. "An Experimental Study of Spontaneous Imbibition in Horn River Shales." University of Alberta.

Mantell. 2013. "Recycling and Reuse of Produced Water to Reduce Freshwater Use in Hydraulic Fracturing Operations." Proceedings of the 2013 EPA Hydraulic Fracturing Study Water Acquisition Workshop, Arlington, VA, June 4.

Marine, I. Wendell, and Steven J. Fritz. 1981. "Osmotic Model to Explain Anomalous Hydraulic Heads." Water Resources Research 17 (1): 73-82. doi:10.1029/WR017i001p00073.

Marmur, Abraham. 1988a. "Penetration of a Small Drop into a Capillary." Journal of Colloid and Interface Science 122 (1): 209-19. doi:10.1016/00219797(88)90304-9.

Marmur, Abraham. 1988b. "The Radial Capillary." Journal of Colloid and Interface Science 124 (1): 301-8. doi:10.1016/0021-9797(88)90351-7.

Marmur, Abraham. 1997. "Line Tension and the Intrinsic Contact Angle in SolidLiquid-Fluid Systems." Journal of Colloid and Interface Science 186 (2): 46266. doi:10.1006/jcis.1996.4666.

Martic, G., T. D. Blake, and J. De Coninck. 2005. "Dynamics of Imbibition into a Pore with a Heterogeneous Surface." Langmuir 21 (24): 11201-7. doi:10.1021/la0513149.

Martin, C. H. 1986. Australasian Coal Mining Practice. Australasian Institute of Mining and Metallurgy.

Meng, Mianmo, Hongkui Ge, Wenming Ji, Yinghao Shen, and Shuai Su. 2015. "Monitor the Process of Shale Spontaneous Imbibition in Co-Current and Counter-Current Displacing Gas by Using Low Field Nuclear Magnetic Resonance Method." Journal of Natural Gas Science and Engineering 27, Part 1 (November): 336-45. doi:10.1016/j.jngse.2015.08.069.

Meng, Mianmo, Hongkui Ge, Wenming Ji, Xiaoqiong Wang, and Lei Chen. 2015. "Investigation on the Variation of Shale Permeability with Spontaneous 
Imbibition Time: Sandstones and Volcanic Rocks as Comparative Study." Journal of Natural Gas Science and Engineering 27, Part 3 (November): 154654. doi:10.1016/j.jngse.2015.10.019.

Mills, Ronald Van Auken, and Roger Clark Wells. 1919. The Evaporation and Concentration of Waters Associated with Petroleum and Natural Gas. U.S. Government Printing Office.

Morsy, Samiha, and J.J. Sheng. 2014. "Imbibition Characteristics of the Barnett Shale Formation." In . Society of Petroleum Engineers. doi:10.2118/168984-MS.

Neuzil, C. E. 2000. "Osmotic Generation of 'anomalous' Fluid Pressures in Geological Environments." Nature 403 (6766): 182-84. doi:10.1038/35003174.

Neuzil, C. E., and A. M. Provost. 2009. "Recent Experimental Data May Point to a Greater Role for Osmotic Pressures in the Subsurface." Water Resources Research 45 (3): W03410. doi:10.1029/2007WR006450.

Nicot, Jean-Philippe, and Bridget R. Scanlon. 2012. "Water Use for Shale-Gas Production in Texas, U.S." Environmental Science \& Technology 46 (6): 358086. doi:10.1021/es204602t.

Nosonovsky, Michael, and Bharat Bhushan. 2009. "Multiscale Effects and Capillary Interactions in Functional Biomimetic Surfaces for Energy Conversion and Green Engineering." Philosophical Transactions of the Royal Society of London A: Mathematical, Physical and Engineering Sciences 367 (1893): 1511-39. doi:10.1098/rsta.2009.0008.

Odusina, Elijah O., Carl H. Sondergeld, and Chandra Shekhar Rai. 2011. "NMR Study of Shale Wettability.” In . Society of Petroleum Engineers. doi:10.2118/147371-MS.

Olphen, H. Van. 1963. An Introduction to Clay Colloid Chemistry: For Clay Technologists, Geologists, and Soil Scientists. Interscience Publishers.

O'Malley, D., S. Karra, R. P. Currier, N. Makedonska, J. D. Hyman, and H. S. Viswanathan. 2015. "Where Does Water Go During Hydraulic Fracturing?" Groundwater, October, n/a-n/a. doi:10.1111/gwat.12380.

Özkaya, Ismail. 1988. "A Simple Analysis of Oil-Induced Fracturing in Sedimentary Rocks." Marine and Petroleum Geology 5 (3): 293-97. doi:10.1016/02648172(88)90008-6.

Parmar, Jaskaran, Hassan Dehghanpour, and Ergun Kuru. 2014. "Displacement of Water by Gas in Propped Fractures: Combined Effects of Gravity, Surface Tension, and Wettability." Journal of Unconventional Oil and Gas Resources 5 (March): 1021. doi:10.1016/j.juogr.2013.11.005.

Philip, J. R. 1957. "Evaporation, and Moisture and Heat Fields in the Soil." Journal of Meteorology $\quad 14 \quad$ (4): $\quad 354-66 . \quad$ doi:10.1175/15200469(1957)014<0354:EAMAHF $>2.0 . \mathrm{CO} ; 2$.

Plug, Willem-Jan, Saikat Mazumder, and Johannes Bruining. 2008. "Capillary Pressure and Wettability Behavior of $\mathrm{CO} 2$ Sequestration in Coal at Elevated Pressures." SPE Journal 13 (4): 455-64. doi:10.2118/108161-PA. 
Rangel-German, E. R., and A. R. Kovscek. 2002. "Experimental and Analytical Study of Multidimensional Imbibition in Fractured Porous Media." Journal of Petroleum Science and Engineering 36 (1-2): 45-60. doi:10.1016/S0920-4105(02)00250-4.

Renock, Devon, Joshua D. Landis, and Mukul Sharma. 2016. "Reductive Weathering of Black Shale and Release of Barium during Hydraulic Fracturing." Applied Geochemistry 65 (February): 73-86. doi:10.1016/j.apgeochem.2015.11.001.

Reyssat, M., L. Y. Sangne, E. A. van Nierop, and H. A. Stone. 2009. "Imbibition in Layered Systems of Packed Beads." EPL (Europhysics Letters) 86 (5): 56002. doi:10.1209/0295-5075/86/56002.

Rieger, Heiko, Christian Thome, and Zeinab Sadjadi. 2015. "Meniscus Arrest Dominated Imbibition Front Roughening in Porous Media with Elongated Pores." Journal of Physics: Conference Series 638 (1): 12007. doi:10.1088/17426596/638/1/012007.

Roshan, H., A. Z. Al-Yaseri, M. Sarmadivaleh, and S. Iglauer. 2016. "On Wettability of Shale Rocks." Journal of Colloid and Interface Science 475 (August): 104-11. doi:10.1016/j.jcis.2016.04.041.

Roshan, H., M. S. Andersen, H. Rutlidge, C. E. Marjo, and R. I. Acworth. 2016. "Investigation of the Kinetics of Water Uptake into Partially Saturated Shales." Water Resources Research 52 (4): 2420-38. doi:10.1002/2015WR017786.

Roshan, H., S. Ehsani, C. E. Marjo, M. S. Andersen, and R. I. Acworth. 2015. "Mechanisms of Water Adsorption into Partially Saturated Fractured Shales: An Experimental Study.” Fuel 159 (November): 628-37. doi:10.1016/j.fuel.2015.07.015.

Rowan, Elisabeth L., Mark A. Engle, Thomas F. Kraemer, Karl T. Schroeder, Richard W. Hammack, and Michael W. Doughten. 2015. "Geochemical and Isotopic Evolution of Water Produced from Middle Devonian Marcellus Shale Gas Wells, Appalachian Basin, Pennsylvania." AAPG Bulletin 99 (2): 181-206. doi:10.1306/07071413146.

Roychaudhuri, Basabdatta, Theodore T. Tsotsis, and Kristian Jessen. 2011. "An Experimental and Numerical Investigation of Spontaneous Imbibition in Gas Shales.” In . Society of Petroleum Engineers. doi:10.2118/147652-MS.

Roychaudhuri, B., T. T. Tsotsis, and K. Jessen. 2013. "An Experimental Investigation of Spontaneous Imbibition in Gas Shales." Journal of Petroleum Science and Engineering 111 (November): 87-97. doi:10.1016/j.petrol.2013.10.002.

Sadjadi, Zeinab, and Heiko Rieger. 2013. "Scaling Theory for Spontaneous Imbibition in Random Networks of Elongated Pores." Physical Review Letters 110 (14): 144502. doi:10.1103/PhysRevLett.110.144502.

Schebarchov, D., and S. C. Hendy. 2008a. "Capillary Absorption of Metal Nanodroplets by Single-Wall Carbon Nanotubes." Nano Letters 8 (8): 2253-57. doi: $10.1021 / \mathrm{n} 1080875 \mathrm{~s}$. 
Schebarchov, D., and S. C. Hendy. 2008b. "Dynamics of Capillary Absorption of Droplets by Carbon Nanotubes." Physical Review E 78 (4): 46309. doi:10.1103/PhysRevE.78.046309.

Schebarchov, D., and S. C. Hendy. 2011. "Uptake and Withdrawal of Droplets from Carbon Nanotubes." Nanoscale 3 (1): 134-41. doi:10.1039/C0NR00477D.

Schlemmer, R., J.E. Friedheim, F.B. Growcock, J.B. Bloys, J.A. Headley, and S.C. Polnaszek. 2002. "Membrane Efficiency in Shale - An Empirical Evaluation of Drilling Fluid Chemistries and Implications for Fluid Design." In . Society of Petroleum Engineers. doi:10.2118/74557-MS.

Settari, A., R.B. Sullivan, and R.C. Bachman. 2002. "The Modeling of the Effect of Water Blockage and Geomechanics in Waterfracs." In . Society of Petroleum Engineers. doi:10.2118/77600-MS.

Shokri, N., P. Lehmann, and D. Or. 2008. "Effects of Hydrophobic Layers on Evaporation from Porous Media." Geophysical Research Letters 35 (19): L19407. doi:10.1029/2008GL035230.

Singh, Harpreet, and Farzam Javadpour. 2013. "A New Non-Empirical Approach to Model Transport of Fluids in Shale Gas Reservoirs." In , 1258-73. Society of Exploration Geophysicists, American Association of Petroleum Geologists, Society of Petroleum Engineers. doi:10.1190/urtec2013-127.

Singh, Harpreet, and Farzam Javadpour. 2016. "Langmuir Slip-Langmuir Sorption Permeability Model of Shale." Fuel 164 (January): 28-37. doi:10.1016/j.fuel.2015.09.073.

Singh, Harpreet, Farzam Javadpour, Amin Ettehadtavakkol, and Hamed Darabi. 2014. "Nonempirical Apparent Permeability of Shale." SPE Reservoir Evaluation \& Engineering 17 (3): 414-24. doi:10.2118/170243-PA.

Stukan, Mikhail R., Patrice Ligneul, John P. Crawshaw, and Edo S. Boek. 2010. "Spontaneous Imbibition in Nanopores of Different Roughness and Wettability." Langmuir 26 (16): 13342-52. doi:10.1021/la101995t.

$\mathrm{Su}$, Shi, Hongwei Chen, Philip Teakle, and Sheng Xue. 2008. "Characteristics of Coal Mine Ventilation Air Flows.” Journal of Environmental Management 86 (1): 4462. doi:10.1016/j.jenvman.2006.11.025.

Sun, Yongpeng, Baojun Bai, and Mingzhen Wei. 2015. "Microfracture and Surfactant Impact on Linear Cocurrent Brine Imbibition in Gas-Saturated Shale." Energy \& Fuels 29 (3): 1438-46. doi:10.1021/ef5025559.

Sundberg, Mark, Alf Månsson, and Sven Tågerud. 2007. "Contact Angle Measurements by Confocal Microscopy for Non-Destructive Microscale Surface Characterization." Journal of Colloid and Interface Science 313 (2): 454-60. doi:10.1016/j.jcis.2007.04.067.

Supple, S., and N. Quirke. 2004. "Molecular Dynamics of Transient Oil Flows in Nanopores I: Imbibition Speeds for Single Wall Carbon Nanotubes." The Journal of Chemical Physics 121 (17): 8571-79. doi:10.1063/1.1796272. 
Takahashi, S., and A. R. Kovscek. 2010. "Spontaneous Countercurrent Imbibition and Forced Displacement Characteristics of Low-Permeability, Siliceous Shale Rocks." Journal of Petroleum Science and Engineering 71 (1-2): 47-55. doi:10.1016/j.petrol.2010.01.003.

Takeda, M., T. Hiratsuka, K. Ito, and S. Finsterle. 2012. "Development and Application of Chemical Osmosis Simulator Based on TOUGH2." In 2012 TOUGH2 Symposium.

Tchistiakov, Alexei Andreevich. 2000. "Colloid Chemistry of In-Situ Clay-Induced Formation Damage." In . Society of Petroleum Engineers. doi:10.2118/58747MS.

Tenan, M. A., S. Hackwood, and G. Beni. 1982. "Friction in Capillary Systems." Journal of Applied Physics 53 (10): 6687-92. doi:10.1063/1.330051.

Teng, Teng, J. G. Wang, Feng Gao, Yang Ju, and Tongqiang Xia. 2016. "Impact of Water Film Evaporation on Gas Transport Property in Fractured Wet Coal Seams." Transport in Porous Media 113 (2): 357-82. doi:10.1007/s11242-0160698-7.

Vandecasteele, Ine, Inés Marí Rivero, Serenella Sala, Claudia Baranzelli, Ricardo Barranco, Okke Batelaan, and Carlo Lavalle. 2015. "Impact of Shale Gas Development on Water Resources: A Case Study in Northern Poland." Environmental Management 55 (6): 1285-99. doi:10.1007/s00267-015-0454-8.

Wang, Dongmei, Raymond Butler, Jin Zhang, and Randall Seright. 2012. "Wettability Survey in Bakken Shale With Surfactant-Formulation Imbibition." SPE Reservoir Evaluation \& Engineering 15 (6): 695-705. doi:10.2118/153853-PA.

Wang, Guijuan, Zhenfeng Zhao, Kai Li, Aifen Li, and Bingqing He. 2015. "Spontaneous Imbibition Laws and the Optimal Formulation of Fracturing Fluid during Hydraulic Fracturing in Ordos Basin." Procedia Engineering, Frontiers in Fluid Mechanics Research, 126: 549-53. doi:10.1016/j.proeng.2015.11.303.

Wang, Junjian, and Sheik S. Rahman. 2016. "Investigation of Water Leakoff Considering the Component Variation and Gas Entrapment in Shale During HydraulicFracturing Stimulation." SPE Reservoir Evaluation \& Engineering, April. doi:10.2118/174392-PA.

Ward, Jill S., and Norman R. Morrow. 1987. "Capillary Pressures and Gas Relative Permeabilities of Low-Permeability Sandstone." SPE Formation Evaluation 2 (3): 345-56. doi:10.2118/13882-PA.

Warner, Nathaniel R., Robert B. Jackson, Thomas H. Darrah, Stephen G. Osborn, Adrian Down, Kaiguang Zhao, Alissa White, and Avner Vengosh. 2012. "Geochemical Evidence for Possible Natural Migration of Marcellus Formation Brine to Shallow Aquifers in Pennsylvania." Proceedings of the National Academy of Sciences 109 (30): 11961-66. doi:10.1073/pnas.1121181109.

Washburn, Edward W. 1921. "The Dynamics of Capillary Flow." Physical Review 17 (3): 273-83. doi:10.1103/PhysRev.17.273. 
Willmott, Geoff R., Chiara Neto, and Shaun C. Hendy. 2011. "Uptake of Water Droplets by Non-Wetting Capillaries." Soft Matter 7 (6): 2357-63. doi:10.1039/C0SM00574F.

Wilson, M. J., L. Wilson, and M. V. Shaldybin. 2016. "Clay Mineralogy and Unconventional Hydrocarbon Shale Reservoirs in the USA. II. Implications of Predominantly Illitic Clays on the Physico-Chemical Properties of Shales." EarthScience Reviews 158 (July): 1-8. doi:10.1016/j.earscirev.2016.04.005.

Winkler, P. M., R. L. McGraw, P. S. Bauer, C. Rentenberger, and P. E. Wagner. 2016. "Direct Determination of Three-Phase Contact Line Properties on Nearly Molecular Scale." Scientific Reports 6 (May): 26111. doi:10.1038/srep26111.

$\mathrm{Xu}, \mathrm{M}$., and H. Dehghanpour. 2014. "Advances in Understanding Wettability of Gas Shales." Energy \& Fuels 28 (7): 4362-75. doi:10.1021/ef500428y.

Yang, Liu, Hongkui Ge, Yinghao Shen, Junjing Zhang, Wei Yan, Shan Wu, and Xianglu Tang. 2015. "Imbibition Inducing Tensile Fractures and Its Influence on in-Situ Stress Analyses: A Case Study of Shale Gas Drilling." Journal of Natural Gas Science and Engineering 26 (September): 927-39. doi:10.1016/j.jngse.2015.07.028.

Yang, Liu, Hongkui Ge, Xian Shi, Yuanfang Cheng, Kunheng Zhang, Hao Chen, Yinghao Shen, Junjing Zhang, and Xiangmei Qu. 2016. "The Effect of Microstructure and Rock Mineralogy on Water Imbibition Characteristics in Tight Reservoirs." Journal of Natural Gas Science and Engineering. Accessed May 19. doi:10.1016/j.jngse.2016.01.002.

Yuan, Yuehua, and T. Randall Lee. 2013. "Contact Angle and Wetting Properties." In Surface Science Techniques, edited by Gianangelo Bracco and Bodil Holst, 3-34. Springer Series in Surface Sciences 51. Springer Berlin Heidelberg. http://link.springer.com/chapter/10.1007/978-3-642-34243-1_1.

Zambrano, Liliana, Per Kent Pedersen, and Roberto Aguilera. 2016. "Geologic Controls on Gas Production and Hydraulic-Fracturing Flowback in Tight Gas Sandstones of the Late Jurassic Monteith Formation, Deep Basin, Alberta, Canada." SPE Reservoir Evaluation \& Engineering 19 (1): 024-040. doi:10.2118/167177-PA.

Zhou, D, L Jia, J Kamath, and A. R Kovscek. 2002. "Scaling of Counter-Current Imbibition Processes in Low-Permeability Porous Media." Journal of Petroleum Science and Engineering, Evaluation of reservoir wettability, 33 (1-3): 61-74. doi:10.1016/S0920-4105(01)00176-0.

Zhou, Zhou, Hazim Abass, Xiaopeng Li, and Tadesse Teklu. 2016. "Experimental Investigation of the Effect of Imbibition on Shale Permeability during Hydraulic Fracturing." Journal of Natural Gas Science and Engineering 29 (February): 413-30. doi:10.1016/j.jngse.2016.01.023.

Zhou, Zhou, B Todd Hoffman, Doug Bearinger, and Xiaopeng Li. 2014. "Experimental and Numerical Study on Spontaneous Imbibition of Fracturing Fluids in Shale Gas Formation.” In . Society of Petroleum Engineers. doi:10.2118/171600-MS. 
Zhu, Pingan, Tiantian Kong, Leyan Lei, Xiaowei Tian, Zhanxiao Kang, and Liqiu Wang. 2016. "Droplet Breakup in Expansion-Contraction Microchannels." Scientific Reports 6 (February): 21527. doi:10.1038/srep21527.

Zolfaghari, Ashkan, Hassan Dehghanpour, Mike Noel, and Doug Bearinger. 2016. "Laboratory and Field Analysis of Flowback Water from Gas Shales." Journal of Unconventional Oil and Gas Resources 14 (June): 113-27. doi:10.1016/j.juogr.2016.03.004. 